\title{
A Coupled Biosphere-Atmosphere Climate Model Suitable for Studies of Climatic Change Due to Land Surface Alterations
}

\author{
Mário Adelmo Varejão-Silva, Sergio H. Franchito, and Vadlamudi Brahmananda Rao \\ Instituto Nacional de Pesquisas Espaciais, INPE, Sao Paulo, Brazil
}

(Manuscript received 24 October 1996, in final form 12 June 1997)

\begin{abstract}
A biosphere model based on BATS (Biosphere-Atmosphere Transfer Scheme) is coupled to a primitive equation global statistical-dynamical model in order to study the climatic impact due to land surface alterations. The fraction of the earth's surface covered by each vegetation type according to BATS is obtained for each latitude belt. In the control experiment, the mean annual zonally averaged climate is well simulated when compared with observations. Deforestation and desertification experiments are performed. In the deforestation experiment, the evergreen broadleaf tree in the Amazonian region is substituted by short grass; in the desertification experiment the semidesert, and the tall grass and deciduous shrubs are substituted by desert and semidesert in the African continent, respectively.

The results show that in both the experiments there is a reduction in evapotranspiration and precipitation in the perturbed region and an increase in the soil surface temperature, the temperature of the foliage air layer, and the foliage temperature. Also, the latent heat flux decreased in the perturbed cases relative to the control case. To partially compensate for the decrease in latent heating, sensible heat flux increased in the perturbed cases compared with the control case. The changes in the deforestation case are greater in the latitude belt centered at $5^{\circ} \mathrm{S}$, where in most part the Amazonian forest is situated. Otherwise, the changes in the desertification are greater in the latitude belt centered at $15^{\circ} \mathrm{N}$. When there is also degradation of the African tropical forest (substitution of evergreen broadleaf trees by short grass), the greatest changes occur southward from that region (in the latitude belt centered at $5^{\circ} \mathrm{N}$ ), and the magnitude of the changes are also increased. This shows the important role of the modification of tropical forest when there is degradation of the vegetation in the African region from $20^{\circ} \mathrm{N}$ to $0^{\circ}$.

The results regarding the changes in the temperature and in the energy fluxes are in agreement with those of earlier experiments carried out with sophisticated general circulation models, which shows the usefulness of this kind of simple model.
\end{abstract}

\section{Introduction}

The biosphere interacts with other components of the climate system on timescales that are characteristic of the life cycles of the vegetation cover. The seasonal cycle of the plant growth depends on the seasonal variations of solar radiation, temperature, and rainfall. The vegetation in turn modifies the exchanges of energy, mass, and momentum between the surface and atmosphere, and plays a major role in the seasonal variations of local surface hydrology. Since the vegetation interacts with the climate, regional and perhaps global impacts can be expected if large areas of vegetation cover are modified.

An efficient tool to predict the climate change due to land surface alterations is the use of different varieties of climate models. For this purpose, numerical models of biosphere, which include the main physiological and

Corresponding author address: Dr. Sergio H. Franchito, INPE, CP 515, 12201-970 Sao Jose dos Campos, São Paulo, Brazil. E-mail: fran@met.inpe.br morphological factors, have been incorporated in some sophisticated general circulation models (GCMs). Some of the biosphere models that are incorporated in GCMs are the following: the Biosphere-Atmosphere Transfer Scheme (BATS) (Dickinson et al. 1986) coupled to the Community Climate Model of the National Center for Atmospheric Research, the Simple Biosphere Model (SiB) (Sellers et al. 1986) coupled to the GCM of the Goddard Laboratory for Atmospheric Science, and the Interaction between Soil, Biosphere, and Atmosphere (ISBA) (Noilhan and Planton 1989) coupled to the GCM of Météo-France. These models have been used for conducting many numerical experiments simulating the climatic response to modifications of the vegetation cover (e.g., Dickinson and Henderson-Sellers 1988; Henderson-Sellers 1990; Nobre et al. 1991; Manzi and Planton 1994; Dirmeyer and Shukla 1994).

Although the GCMs are commonly used in climate change studies, they involve many complex processes so that it is difficult to identify the cause of certain effects. So, simple climate models like the statisticaldynamical models (SDMs) are very useful in this con- 
text. Also, they are computationally more economical for conducting a large number of experiments concerning long-term climatic changes.

In spite of the usefulness of the SDMs only a few studies have been made with this type of model to evaluate the climatic impact due to land surface modifications. One of the pionering studies in this context was made by Charney et al. (1975). They used a quasigeostrophic model without the hydrological cycle and showed that the increase of the albedo produced subsidence, which perpetuated desert conditions. Potter et al. (1975) and Ellsaesser et al. (1976), by modifying the land surface albedo, conducted deforestation and desertification experiments, respectively. Gutman et al. (1984), using a version of the Ohring and Adler (1978) hemispheric quasigeostrophic SDM, incorporated a simple parameterization of biofeedback mechanism, which links the surface state to the atmospheric processes. Gutman (1984) used this model for studying the hemispheric response of land surface alterations like desertification, deforestation, and irrigation. Franchito and Rao (1992) extended this study for both the hemispheres using a global primitive equation SDM. Recently, Zhang (1994) developed a biosphere model based on BATS suitable for SDMs. The equations of BATS were adapted to the energy flux formulations proposed by Saltzman and Vernekar (1971), which are commonly used in SDMs (e.g., Saltzman and Vernekar 1972; Taylor 1980; Franchito and Rao 1991, 1992, 1995; Rao and Franchito 1993; Oglesby and Saltzman 1990). Although this biosphere model is suitable for SDMs, only tests with the vegetation model decoupled from the SDM were made.

The inclusion of a biosphere model like BATS in a SDM is very useful for studying climatic change due to land surface alterations. As mentioned earlier, the biosphere is an interactive element in the climate system. Over timescales of hundreds to thousands of years man's activities (agricultural, grazing, and building practices) may affect the biosphere (Gates 1988). Otherwise, changes in the biosphere may have significant impact on local and global climate (Sagan et al. 1979; Budyko 1982). Therefore, there is need of an interactive atmosphere model in order to simulate the long-term climatic changes.

However, it is difficult to design an interactive model that simulates realistically all the feedback mechanisms between the biosphere and the other elements of the climate system because sufficient knowledge of the biosphere processes is still lacking. In this context, comprehensive models like BATS are very useful. Although these models are simpler than the real atmosphere, they are based on simplifications, which may suggest an adequate treatment of the land surface processes in a climate model (Zhang 1994; Dickinson 1992). As mentioned earlier, these well-elaborated biosphere models have been incorporated in GCMs. However, their coupling to SDMs is also relevant in studies of the interactions between the vegetation and climate. Besides, the
SDMs greatly simplify analysis and help in identifying biogeophysical mechanisms. Thus, BATS seems to be very useful in this context.

The objective of this paper is to couple the parameterization of the vegetation proposed by Zhang (1994) with a SDM. The model will be used for two purposes: 1) running a coupled model to simulate the global climate and the surface fluxes in the geobotanic zones, and 2) investigating the climatic response to land surface modifications like deforestation and desertification. Comparisons with experiments conducted with GCMs are also made. The SDM used in this study is that developed by Franchito and Rao (1992), where the original parameterizations of the surface and atmospheric fluxes are modified by adapting the vegetation model proposed by Zhang (1994). To couple the models, new parameterizations of the fluxes relative to the fraction of the earth's surface covered by ocean ice, and snow following a similar procedure as in Zhang (1994), are developed. So, the surface and atmospheric fluxes are obtained for the whole latitude belt.

In section 2 the vegetation model and the formulations of the heat fluxes are presented. The coupling with the SDM is shown in section 3. In section 4 the principal results are discussed. Section 5 contains the summary and conclusions.

\section{The vegetation model}

The biosphere model is the same as that developed by Zhang (1994). In that model the equations of BATS were adapted to the energy flux formulations proposed by Saltzman and Vernekar (1971). For this purpose, the expressions of BATS were used in the original form or with some modifications or even substituted by equations of the SDM. BATS initially was developed for a multilevel GCM, which has a detailed parameterization of the planetary boundary layer and contains a soil model. The original SDM of Saltzman and Vernekar (1971) has two atmospheric layers (surface-500 hPa, and 500 hPa-top of the atmosphere) and a subsurface layer, which has a fixed temperature. So, the energy fluxes from surface to atmosphere in the SDM are related to the temperatures at surface and at $500 \mathrm{hPa}$. To adapt BATS to the two-layer SDM, Zhang (1994) assumed that the model contains four domains: the subsurface layer, the foliage layer, the foliage air layer, and the atmospheric layer (Fig. 1). The model involves parameterizations of the energy balance of the earth's surface, the energy and moisture balances of the foliage air layer, and the energy balance of the foliage. A brief description of the biosphere model relations is given below.

The components of the surface heating, like the shortwave radiation, longwave radiation, sensible and latent heat fluxes, and the subsurface heat flux, have similar forms as those given in Saltzman and Vernekar (1971) but with the inclusion of the vegetation effect. These 


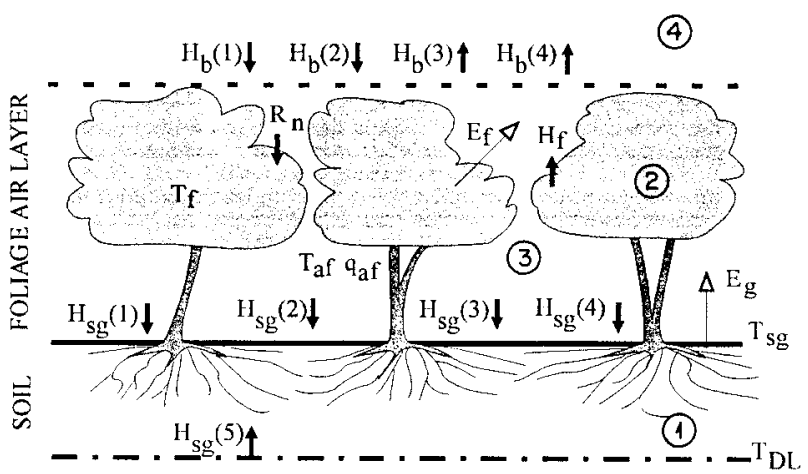

FIG. 1. The biosphere model scheme. The four domains of the model are indicated: 1) the subsurface layer, 2) the foliage layer, 3) the foliage air layer, and 4) the atmosphere above. The components of the surface heating are indicated: $H_{\mathrm{sg}}(i), i=1,5$, are the fluxes (shortwave radiation, longwave radiation, sensible heat, flux, latent heat flux, and subsurface heat flux) at the interface between the soil surface and the air above it; $H_{\mathrm{b}}(i), i=1,4$, are the fluxes (shortwave radiation, longwave radiation, sensible heat flux, and latent heat flux) at the top of the foliage air layer; $T_{\mathrm{s}}$ is the soil surface temperature; $T_{\mathrm{f}}$ and $T_{\text {af }}$ are the foliage and foliage air-layer temperatures; and $T_{\mathrm{dl}}$ is the subsurface temperature. The arrows indicate the direction of the fluxes (source: Zhang 1994).

fluxes are calculated both at the interface between the soil surface and the air above it, and at the top of the foliage air layer. The formulations of these surface fluxes are shown in Tables 1 and 2, and the meaning of the symbols are given in the appendix.

Regarding Tables 1 and 2, the thermal emissivities of the earth's surface $\left(\varepsilon_{\mathrm{s}}\right)$ and of the foliage $\left(\varepsilon_{\mathrm{f}}\right)$ are given by $1-r_{\mathrm{sIR}}$ and $1-r_{\mathrm{fIR}}$, respectively, where $r_{\mathrm{sIR}}\left(=2 r_{\mathrm{s}}\right)$ and $r_{\mathrm{fIR}}$ are the longwave albedos of the earth's surface and of the foliage, respectively. Also, $h=\rho_{\mathrm{a}} C_{\mathrm{p}} C_{\mathrm{D}}[(1$ $\left.\left.-\sigma_{\mathrm{f}}\right) V_{\mathrm{a}}+\sigma_{\mathrm{f}} U_{\mathrm{af}}\right]$, and $C_{\mathrm{D}}=\sigma_{\mathrm{f}} C_{\mathrm{DV}}+\left(1-\sigma_{\mathrm{f}}\right) C_{\mathrm{DL}}$, where $C_{\mathrm{DV}}=\left[K_{\mathrm{vk}} / \ln \left(z_{1} / z_{\mathrm{ov}}\right)\right]^{2}$ is the drag coefficient over vegetation, and $C_{\mathrm{DL}}=\left[K_{\mathrm{vk}} / \ln \left(z_{1} / z_{\mathrm{oL}}\right)\right]^{2}$ is the drag coefficient over land. Here, $\sigma_{\mathrm{f}}, r_{\mathrm{fIR}}$, and $z_{\mathrm{ov}}$ are obtained from BATS for each type of vegetation; $r_{\mathrm{s}}=0.2$; and $z_{\mathrm{oL}}=0.01 \mathrm{~m}$. The wind speed in the foliage layer is equal to $V_{\mathrm{a}}\left(C_{\mathrm{D}}\right)^{1 / 2}$, where $V_{\mathrm{a}}$ is the wind speed at the anemometer level; $\mathrm{b}_{2}$ and $\mathrm{c}_{2}$ are prescribed constants as in Saltzman and Vernekar (1971). In the present model the value of $c_{2}$ is modified $\left(=-115 \mathrm{~W} \mathrm{~m}^{-2}\right)$ in order to couple the vegetation model to the SDM developed by Franchito and Rao (1992).

The energy balance at the interface between the soil surface and the air above it is given by
$H_{\mathrm{sg}}(1) \downarrow+H_{\mathrm{sg}}(2) \downarrow+H_{\mathrm{sg}}(3) \downarrow+H_{\mathrm{sg}}(4) \downarrow+H_{\mathrm{sg}}(5) \uparrow=0$,

where the arrows indicate the direction of the fluxes, and $H_{\mathrm{sg}}(i) \downarrow=-H_{\mathrm{sg}}(i) \uparrow$.

The energy balance of the foliage air layer assumes that the heat fluxes from ground and from the foliage are balanced by the heat flux to the atmosphere:

$$
H_{\mathrm{b}}(3) \uparrow=H_{\mathrm{sg}}(3) \uparrow+H_{\mathrm{f}} .
$$

The heat flux from foliage to the foliage air layer is parameterized like in BATS:

$$
H_{\mathrm{f}}=\sigma_{\mathrm{f}} L_{\text {sai }} \rho_{\mathrm{a}} C_{\mathrm{p}}\left(T_{\mathrm{f}}-T_{\mathrm{af}}\right) / r_{\mathrm{la}},
$$

where $T_{\mathrm{f}}$ and $T_{\text {af }}$ are the foliage and the foliage air layer temperatures, respectively; $L_{\text {sai }}$ is the leaf-stem area index (equal to the sum of the leaf area index, $L_{\mathrm{ai}}$, and the stem area index, $S_{\mathrm{ai}}$ ); and $r_{\mathrm{la}}$ is the resistance to heat or moisture transfer through the laminar boundary layer at the foliage surface.

The moisture balance of the foliage air layer assumes that the water vapor flux from soil surface and from the foliage are balanced by the water vapor flux to the atmosphere:

$$
E_{\mathrm{b}}=E_{\mathrm{g}}+E_{\mathrm{f}},
$$

where $E_{\mathrm{g}}=H_{\mathrm{sg}}(4) \uparrow / L$ and the water vapor flux from the foliage air layer to atmosphere is given by $E_{\mathrm{b}}=$ $H_{\mathrm{b}}(4) \uparrow / L$. In the expression for $H_{\mathrm{b}}(4) \uparrow$ (see Table 2), $e_{2}(=2.4445)$ and $f_{2}\left(=70.7827 \mathrm{~W} \mathrm{~m}^{-2}\right)$ are prescribed constants; $w\left(=q_{\mathrm{af}} / q_{\mathrm{afs}}\right)$ is the relative humidity of the foliage air layer; $q_{\mathrm{af}}$ is the water vapor mixing ratio; and $q_{\text {afs }}$ is the saturated water vapor mixing ratio corresponding to the temperature of the foliage air layer:

$$
\begin{aligned}
q_{\mathrm{afs}}= & 0.622 / 1000 \times 6.1078 \\
& \times \exp \left[\mathrm{a}_{3}\left(T_{\mathrm{af}}-273.16\right) /\left(T_{\mathrm{af}}-\mathrm{b}_{3}\right)\right],
\end{aligned}
$$

where $a_{3}$ and $b_{3}$ are constants that have different values for water and ice.

The water vapor flux from the foliage to the foliage air layer is parameterized according to BATS:

$$
E_{\mathrm{f}}=r^{\prime \prime} E_{\mathrm{f}}^{\mathrm{WET}}
$$

with

\begin{tabular}{|c|c|}
\hline$i \quad H_{\mathrm{sg}}(i)$ & Parameterization \\
\hline $\begin{array}{l}1 \downarrow \text { shortwave radiation } \\
2 \downarrow \text { longwave radiation } \\
3 \downarrow \text { sensible heat flux } \\
4 \downarrow \text { latent heat flux } \\
5 \uparrow \text { subsurface heat flux }\end{array}$ & $\begin{array}{c}\left(1-\sigma_{\mathrm{f}}\right)(1-\chi)\left(1-r_{\mathrm{s}}\right)\left(1-r_{\mathrm{a}}\right) R_{\mathrm{o}} \\
\sigma_{\mathrm{B}}\left[\left(1-\sigma_{\mathrm{f}}\right)\left(\nu_{1} T_{2}^{4}-T_{\mathrm{sg}}^{4}\right) /\left(1 / \varepsilon_{\mathrm{a}}+1 / \varepsilon_{\mathrm{s}}-1\right)+\sigma_{\mathrm{f}}\left(T_{\mathrm{f}}^{4}-T_{\mathrm{sg}}^{4}\right) /\left(1 / \varepsilon_{\mathrm{f}}+1 / \varepsilon_{\mathrm{s}}-1\right)\right] \\
-h\left(T_{\mathrm{sg}}-T_{\mathrm{af}}\right) \\
-L h f_{\mathrm{g}} / \mathrm{c}_{\mathrm{p}}\left(q_{\mathrm{gs}}-q_{\mathrm{af}}\right) \\
-k\left(T_{\mathrm{sg}}-T_{\mathrm{dl}}\right)\end{array}$ \\
\hline
\end{tabular}

$$
\begin{gathered}
r^{\prime \prime}=1-\delta\left(E_{\mathrm{f}}^{\mathrm{WET}}\right)\left\{1-L_{\mathrm{w}}-L_{\mathrm{d}}\left[r_{1 \mathrm{a}} /\left(r_{1 \mathrm{a}}+r_{\mathrm{stom}}\right)\right]\right\} \\
E_{\mathrm{f}}^{\mathrm{WET}}=\sigma_{\mathrm{f}} L_{\mathrm{sa}} \rho_{\mathrm{a}}\left(q_{\mathrm{fs}}-q_{\mathrm{af}}\right) / r_{1 \mathrm{a}} .
\end{gathered}
$$

TABLE 1. Functional forms for the heat fluxes at the interface between soil surface and the air above it $\left[H_{\mathrm{sg}}(i)\right]$. The arrows indicate the direction of the fluxes. 
TABLE 2. Functional forms for the heat fluxes at the top of the foliage air layer $\left[H_{\mathrm{b}}(i)\right]$. The downward and upward arrows indicate the direction of the fluxes.

\begin{tabular}{lcc}
\hline \hline$i$ & \multicolumn{1}{c}{$H_{\mathrm{b}}(i)$} & Parameterization \\
\hline $1 \downarrow$ shortwave radiation & $\sigma_{\mathrm{f}}(1-\chi)\left(1-r_{\mathrm{a}}\right)\left(1-r_{\mathrm{f}}\right) R_{\mathrm{o}}$ \\
$2 \downarrow$ longwave radiation & $\sigma_{\mathrm{f}}\left[\sigma_{\mathrm{B}}\left(T_{\mathrm{sg}}^{4}-T_{\mathrm{f}}^{4}\right) /\left(1 / \varepsilon_{\mathrm{s}}+1 / \varepsilon_{\mathrm{f}}-1\right)+\sigma_{\mathrm{B}}\left(\nu_{1} T_{2}^{4}-T_{\mathrm{f}}^{4}\right) /\left(1 / \varepsilon_{\mathrm{a}}+1 / \varepsilon_{\mathrm{f}}-1\right)\right]$ \\
$3 \uparrow$ sensible heat flux & {$\left[\mathrm{b}_{2}\left(T_{\mathrm{af}}-T_{2}\right)+\mathrm{c}_{2}\right] C_{\mathrm{D}} / C_{\mathrm{DB}}$} \\
4 & $\left.w\left[e_{2} H_{\mathrm{b}}(3)+f_{2}\right)\right]$ \\
\hline
\end{tabular}

In the expression above $L_{\mathrm{w}}\left(=\left[W_{\mathrm{dew}} / W_{\mathrm{dmax}}\right]^{2 / 3}\right)$ is the fractional area of the leaves covered by water, where $W_{\text {dew }}$ is the total rainfall intercepted by the canopy and $W_{\text {dmax }}$ is the capacity of the canopy to intercept rainwater; $L_{\mathrm{d}}$ is the fractional area of the leaves free to transpire; $r_{\text {stom }}$ is the stomatal resistance; $\delta\left(E_{\mathrm{f}}^{\mathrm{WET}}\right)$ is a function equal to unity (zero) if $E_{\mathrm{f}}^{\text {WET }}$ is positive (negative); $q_{\mathrm{fs}}$ is the saturated mixing ratio at the foliage, which has similar expression as Eq. (5) except that $T_{\text {af }}$ is replaced by $T_{\mathrm{f}}$. The stomatal resistence is calculated as $r_{\text {smin }} \times R_{1} \times S_{1} \times M_{1}$, where $r_{\text {smin }}$ is the minimum stomatal resistence (obtained from BATS for each type of vegetation); $R_{1}$ and $S_{1}$ are functions of solar radiation and $T_{\mathrm{f}}$, respectively; and $M_{1}$ is the soil moisture factor.

The energy balance of the foliage assumes that the net radiation absorbed by the foliage is balanced by the sensible $\left(H_{\mathrm{f}}\right)$ and latent $\left(L E_{\mathrm{f}}\right)$ fluxes from the foliage to the foliage air layer:

$$
R_{\mathrm{n}}=H_{\mathrm{f}}+L E_{\mathrm{f}},
$$

where $R_{\mathrm{n}}=H_{\mathrm{b}}(1) \downarrow+H_{\mathrm{b}}(2) \downarrow$.

Substitution of the relations given in Tables 1 and 2 together with the surface flux parameterizations from BATS [Eqs. (3) and (6)] into the expressions (1), (2), (4), and (9), along with the expressions for the saturated mixing ratio [Eq. (5)] produces a closed system with seven unknow variables: $T_{\mathrm{sg}}, T_{\mathrm{f}}, T_{\mathrm{af}}, q_{\mathrm{af}}, q_{\mathrm{gs}}, q_{\mathrm{fs}}$, and $q_{\text {afs }}$, which must be solved by an interactive method. In the present paper we use a Newton-Raphson method for simultaneous solution of nonlinear equation system (Demidovich and Marion 1976).

Thus, given the temperature at $500 \mathrm{hPa}$, the wind speed at the anemometer level, and the subsurface temperature, the vegetation model provides the surface fluxes. More details regarding the vegetation model are given in Zhang (1994).

\section{Coupling with the SDM}

The SDM used in the present work is that developed by Franchito and Rao (1992). The model is a two-layer global primitive equation model in sigma-coordinate and includes parameterizations of friction, diabatic heating, and large-scale eddies. The components of atmospheric and surface fluxes, like the shortwave radiation, longwave radiation, small-scale convection, and subsurface flux, have forms similar to those proposed by Saltzman (1968) and Saltzman and Vernekar (1971), and the parameterization of latent heat release is based on that used by Gutman et al. (1984). These energy fluxes are computed for the entire latitude belt. The surface albedo, the factor proportional to the conductive capacity of the surface medium, and the subsurface temperature depend on the type of surface (Saltzman and Vernekar 1972). More details about the SDM are given in Franchito and Rao (1992, 1995).

In the present paper, the original parameterizations of the atmospheric and surface fluxes given by Franchito and Rao (1992) are modified in order to couple to the biosphere model based on BATS (hereafter called coupled model). For coupling the models, the energy fluxes are computed separately for the land fraction and the remaining part (covered by ocean-ice-snow) of the latitude belt: for the land fraction of the latitude belt, parameterizations of the biosphere model described in the last section are used; for the remaining part of the latitude belt covered by ocean-ice-snow, new parameterizations similar to those given in section 2 are developed. The energy fluxes in the entire latitude belt are obtained through the weighted mean of these fluxes computed separately in the land and in the ocean-icesnow areas using as weight the fractions of them in the latitude belt.

The coupled model contains different domains according to the areas where the energy fluxes are computed: for the land fraction of the latitude belt there are four domains (section 2): the subsurface layer, the foliage and the foliage air layer, and the air above the foliage layer divided in two atmospheric layers; for the remaining part of the latitude belt, three domains are considered: the subsurface layer, the air layer adjacent to the surface, and the two atmospheric layers above it. Thus, the model surface in the land fraction of the latitude belt contains soil and foliage, and in the case of the remaining portion of the latitude belt the model surface is constituted by ocean-ice-snow.

In his paper, Zhang (1994) made tests only with the biosphere model decoupled from the SDM. So, his model was applied considering a point over surface covered by only one type of vegetation each time. In the present study, however, there are several different types of vegetation at the same time in a latitude belt. So, the fraction of the earth's surface covered by each type of vegetation is obtained. This is made using the data archive prepared by Manzi and Planton (1994), which has $1^{\circ} \times 1^{\circ}$ resolution (Fig. 2). For the land fraction of a latitude belt, parameters like surface albedo, drag coefficient, stem area index, etc. are obtained through the weighted mean 


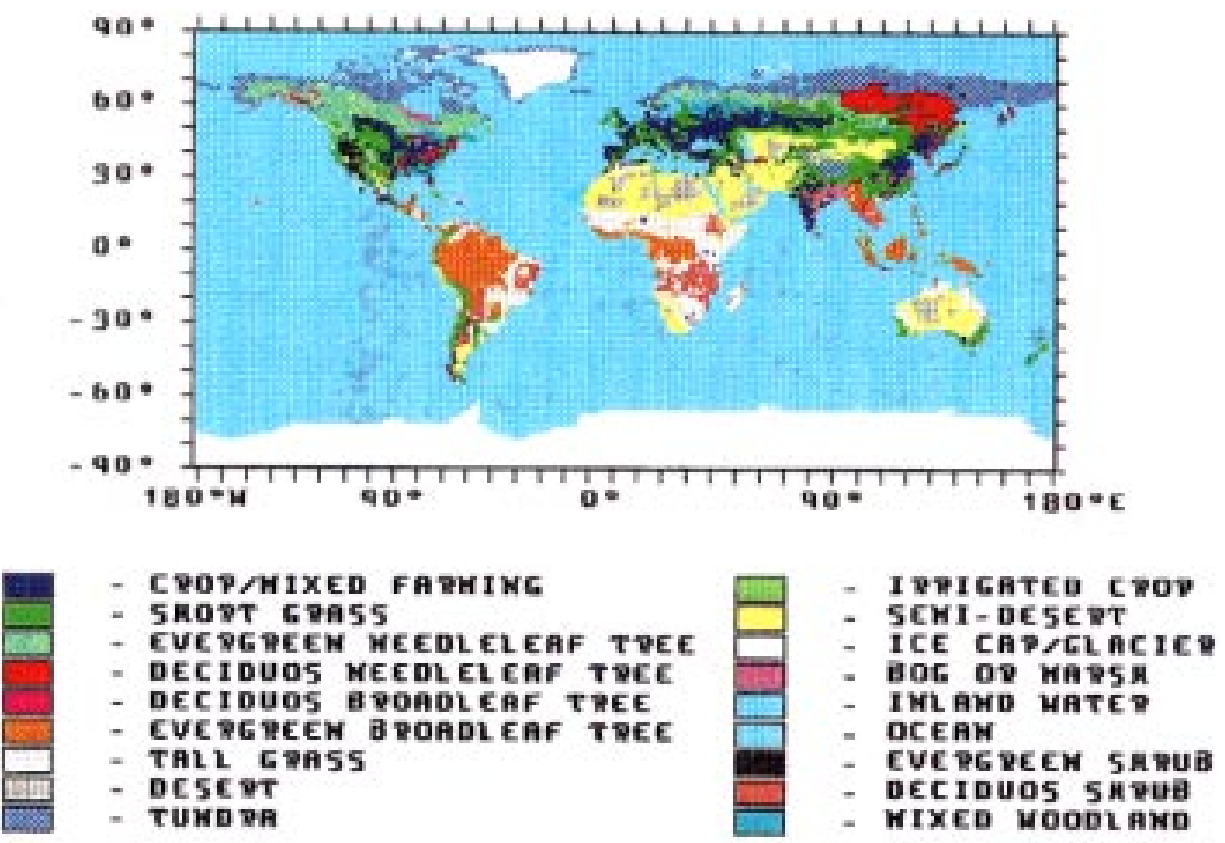

FIG. 2. Distribution of the vegetation types according to the classification given in BATS. The data, with $1^{\circ} \times 1^{\circ}$, are from Manzi and Planton (1994).

of the specific values of the variables given in BATS using as weight the fraction of land occuped by each vegetation type. Similar procedure is adopted to obtain the fractions covered by ocean and ice.

\section{a. Surface flux parameterizations for the land fraction of a latitude belt}

Since the model surface in the land fraction of a latitude belt is composed by soil and foliage, the energy fluxes are computed taking into account both these effects. So, the shortwave and longwave radiation fluxes at the model surface are given by the sum of the flux at the interface between soil surface and the air above it, and the flux at the top of the foliage air layer:

$$
\begin{aligned}
& \bar{H}_{\mathrm{sv}}(1) \downarrow=\bar{H}_{\mathrm{sg}}(1) \downarrow+\bar{H}_{\mathrm{b}}(1) \downarrow, \\
& \bar{H}_{\mathrm{sv}}(2) \downarrow=\bar{H}_{\mathrm{sg}}(2) \downarrow+\bar{H}_{\mathrm{b}}(2) \downarrow,
\end{aligned}
$$

where the bars correspond to the zonal average considering only the land surface fraction of the earth's surface.

In the coupled model, the sensible $\left[\bar{H}_{\text {sv }}(3) \uparrow\right]$ and latent heat $\left[\bar{H}_{\mathrm{sv}}(4) \uparrow\right]$ from surface to the atmosphere for the land fraction of the latitude belt are equal to the sum of these fluxes from soil and foliage. So, they are equal to $\bar{H}_{\mathrm{b}}(3) \uparrow$ and $\bar{H}_{\mathrm{b}}(4) \uparrow$, respectively [see Eqs. (2) and (4)]. Also, the subsurface heat flux $\left[\bar{H}_{\mathrm{sv}}(5)\right] \uparrow$ is equal to $\bar{H}_{\mathrm{sg}}(5) \uparrow$. The formulation of these fluxes are summarized in Table 3 . The method to compute the values of $\bar{T}_{\mathrm{sg}}, \bar{T}_{\mathrm{af}}, \bar{T}_{\mathrm{f}}, \bar{q}_{\mathrm{af}}, \bar{q}_{\mathrm{gs}}, \bar{q}_{\mathrm{fs}}$, and $\bar{q}_{\mathrm{afs}}$ is the same as that described in section 2 .

The formulation of $H_{\mathrm{b}}(4) \uparrow$ (Table 2) is similar to that proposed by Saltzman and Vernekar (1971). The difference between the two expressions is in the meaning of the variable $w$. While in the SDM of Saltzman and Vernekar (1971) $w$ is the water availability parameter, $w$ in the biosphere model is the ratio $q_{\mathrm{af}} / q_{\mathrm{afs}}$, called relative humidity of the foliage air layer (Zhang 1994). This ratio has an important role in the partition of the surface net radiation into sensible and latent heat fluxes (the subsurface conduction flux is negligibly small for mean annual and seasonally averaged conditions). Since there are uncertainties in the determination of the water availability on land this substitution may be not adequate. Thus, Zhang (1994) proposed the use of a nondimensional adjustable factor $(Y)$ for the relative humidity $\left(Y q_{\mathrm{af}} / q_{\mathrm{afs}}\right)$. The values of $Y$ used in his work were tuned in order that the results of the sensitivity experiments carried out with the biosphere model are similar to those obtained from GCMs.

In the present work, we use one value of $Y$ for each type of surface (Table 4). Thus, the values of $Y$ for the land fraction of a latitude belt are obtained through the weighted mean of the $Y$ values for each vegetation type using as weight the fraction of land in a latitude belt covered by each kind of vegetation. We made tests on the effects of the variation of $Y$ on the partition of the available energy into the latent and sensible heat fluxes, which showed that the latent (sensible) heat flux increases (decreases) with the increase (decrease) of $Y$. So, the values of $Y$ for the coupled model must be obtained taking into account that the several types of surfaces have different partitions of the available energy into sensible and latent heat fluxes. For example, in the 

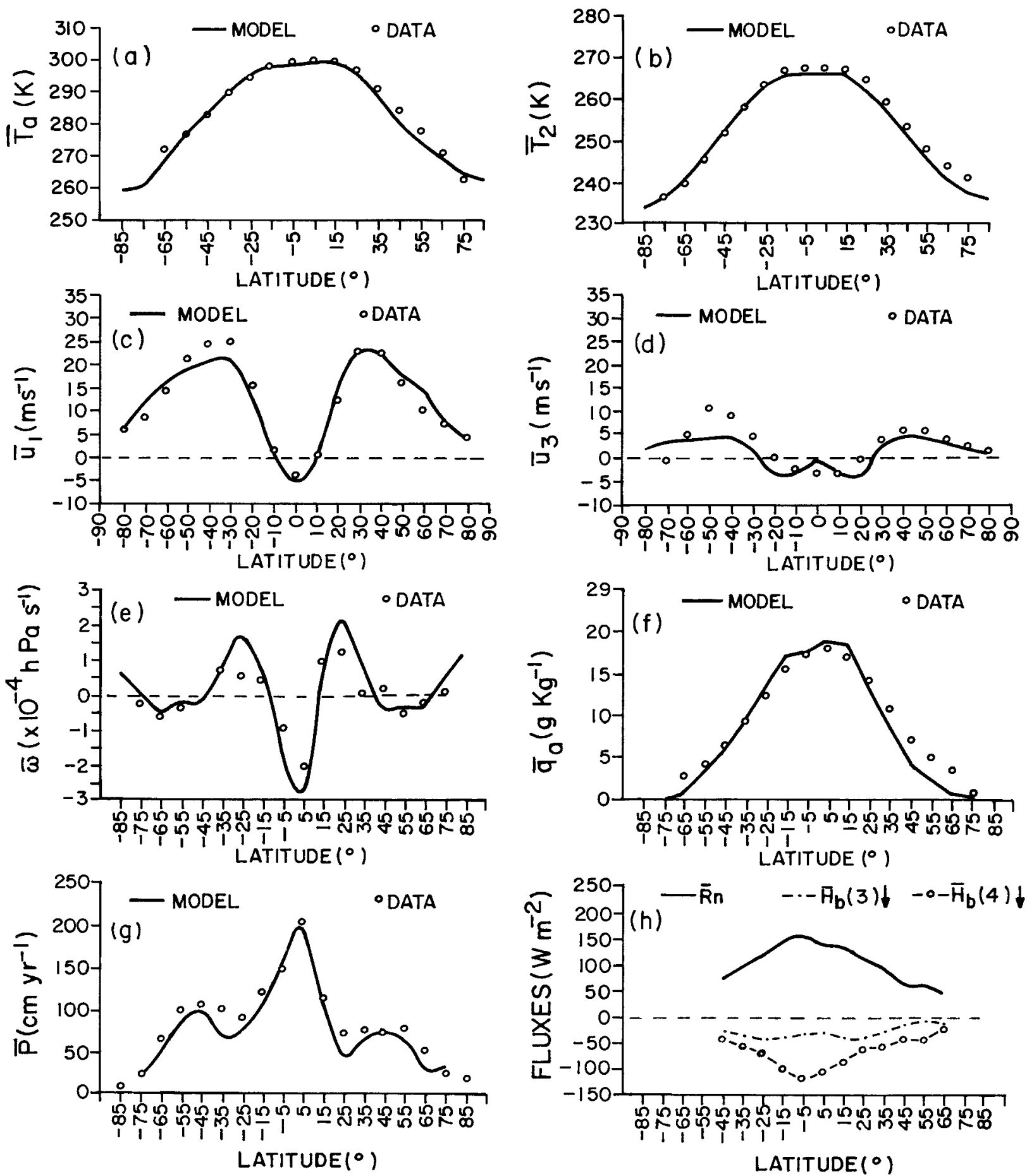

FIG. 3. Simulation of the mean annual zonally averaged characteristics: (a) air surface temperature; (b) 500-hPa temperature; (c) zonal wind at $250 \mathrm{hPa}$; (d) zonal wind at $750 \mathrm{hPa}$; (e) zonally averaged vertical velocity $\bar{\omega}$ at $500 \mathrm{hPa}$; (f) specific humidity at surface; (g) precipitation [the observations are obtained from Oort (1983), except for the precipitation where the data are those from Budyko (1978)]; and (h) surface net radiation and sensible and latent heat fluxes in the continental portion of the latitude belt.

case of the evergreen and deciduous broadleaf trees the energy partition occurs mainly in the form of latent heat flux (so, the values of $Y$ must be larger); whereas, in the case of semidesert and ice cap/glacier the energy partition into the form of sensible heat flux increases in comparison with the case of forest (so, the values of $Y$ must be smaller than those for forest). Also, $Y$ must be larger than 0.4 (Zhang 1994). Taking into account the 
TABLE 3. Parameterizations of the surface $\left[\bar{H}_{\mathrm{sv}}(i)\right]$ and atmospheric $\left[\bar{H}_{\mathrm{av}}(i)\right]$ fluxes for the land fraction of a latitude belt. The arrows indicate the direction of the fluxes.

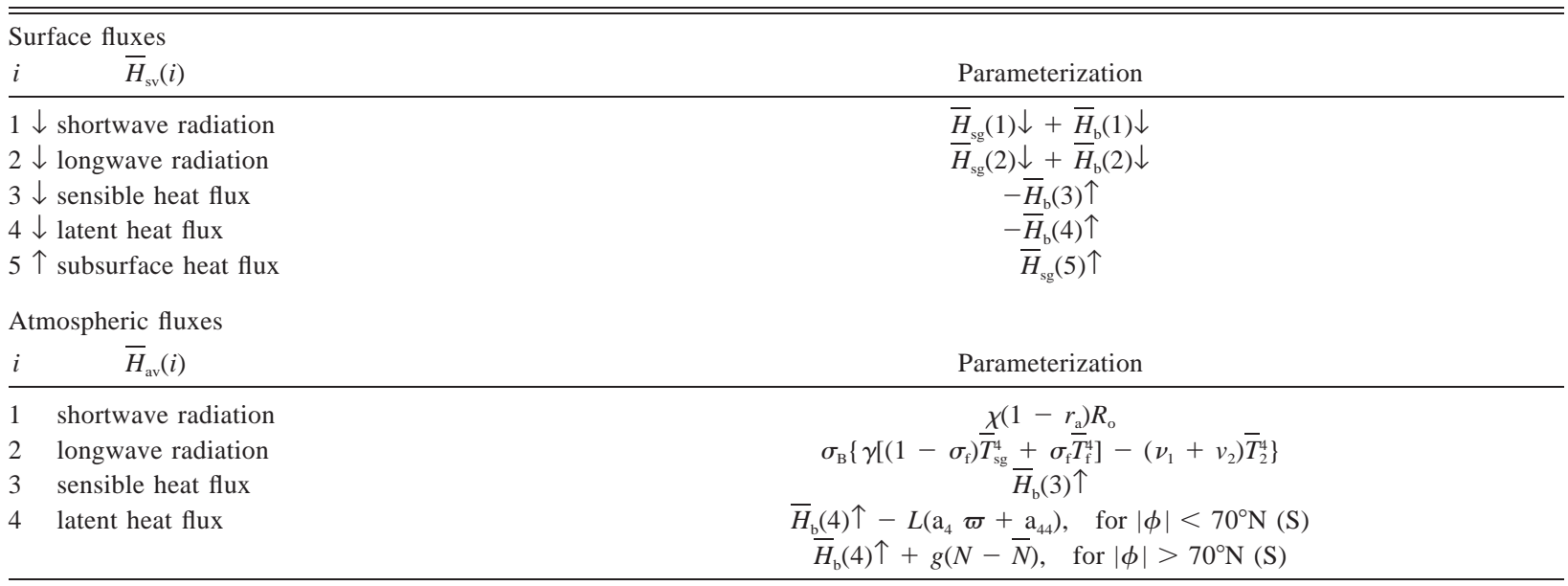

reasons given above, we tested several values of $Y$ in the coupled model in order to simulate the mean annual zonally averaged state. There was good agreement between the simulations and the observations (see section 4a) when the values of $Y$ given in Table 4 were used. So, we adopted them for the coupled model.

As it is shown in section 2, the water vapor flux from the foliage to the foliage air layer depends on the parameter $W_{\mathrm{dw}}=W_{\mathrm{dew}} / W_{\mathrm{dmax}}$, which has an important influence on land surface processes. Zhang (1994) tested several values of $W_{\mathrm{dw}}$ and noted that the biosphere model was sensitive to values of $W_{\mathrm{dw}}$ between 0.0 and 0.2 , mainly when they were near 0.0 . In the present model, as in the case of $Y$, we use one value of $W_{\mathrm{dw}}$ for each type of vegetation (Table 4). For mean annual conditions, the vegetation remains wet only during a relatively short time, so that the values of $W_{\mathrm{dw}}$ must be small. To choose the values of $W_{\mathrm{dw}}$ to be used in the coupled model we took into consideration the number of hours during the day and the number of the months in the year in which the leaves must remain wet. For example, in the case of the evergreen broadleaf trees, we supposed that the foliage remains wet about $2.5 \mathrm{~h}$ each day during six months (so: $2.5 / 24 \times 6 / 12=0.052$ ). For the case of the crop/mixed farming and short grass, we assumed that the foliage remains wet $2 \mathrm{~h}$ during a day during six months, etc. The values of $W_{\mathrm{dw}}$ given in Table 4 were used in the coupled model in order to simulate the mean annual zonally averaged conditions. The zonally averaged values of $W_{\mathrm{dw}}$ are obtained in the same way as in the case of those for $Y$. The results showed good agreement with the observations (see section 4a). So, we adopted these values for the coupled model.

Since the biosphere model has no soil hydrology, the value of the soil water availability $\left(f_{\mathrm{g}}\right)$ must be specified. For a dense and thick vegetation cover, the soil surface temperature, the foliage temperature, the foliage air layer temperature, and vapor pressure of the air within the foliage are practically insensitive to the values of $f_{\mathrm{g}}$ (Zhang 1994). In the present model, we also assumed
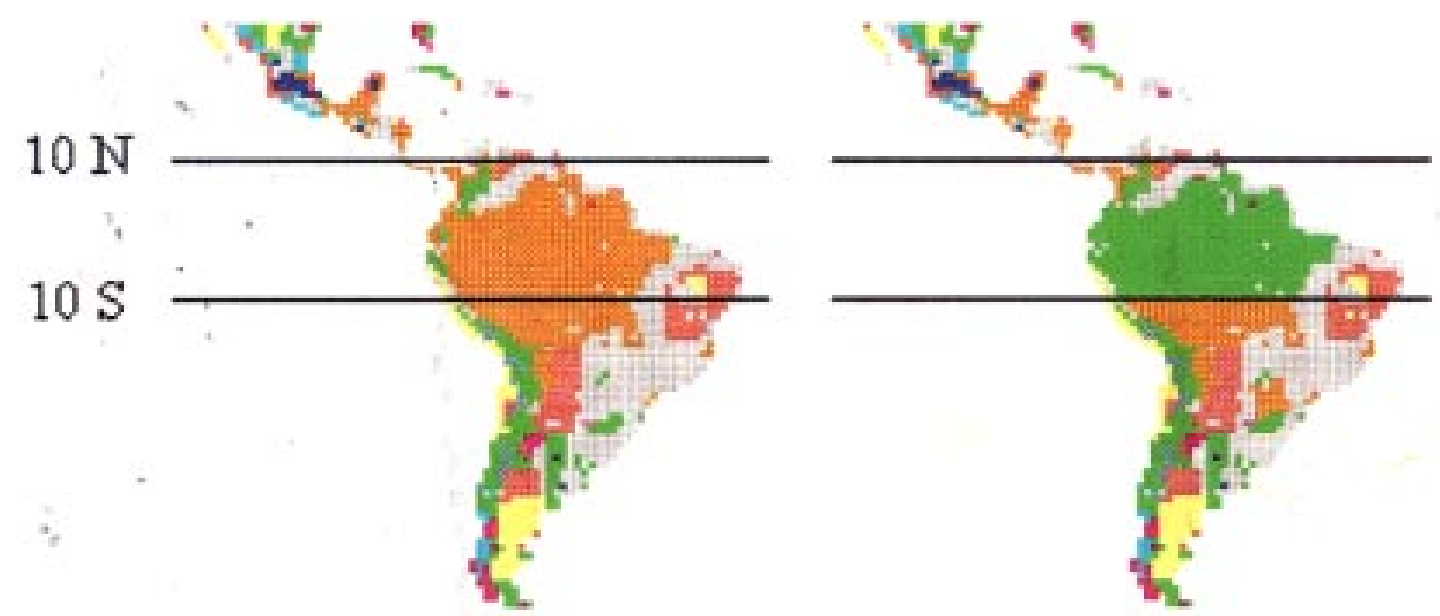

FIG. 4. Amazonian deforestation experiment: control case (left) and perturbed case (right). The legend colors are the same as in Fig. 2. 


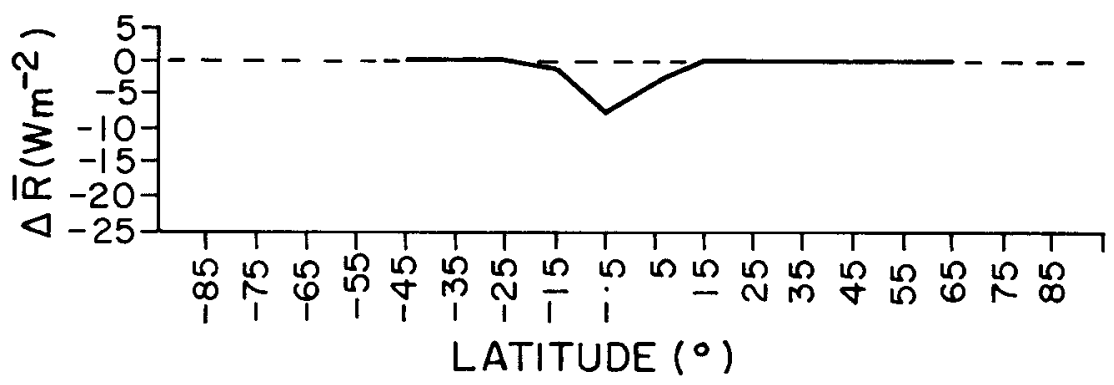

FIG. 5. Changes in the surface net radiation (perturbed minus control case) in the continental portion of the latitude belt for the deforestation experiment.

one value of $f_{\mathrm{g}}$ for each type of vegetation. The procedure of the selection of $f_{\mathrm{g}}$ was similar to that for $W_{\mathrm{dw}}$.

Although the method in which the values of $W_{\mathrm{dw}}, Y$, and $f_{\mathrm{g}}$ were tuned to the coupled model seems to be somewhat arbitrary, the results regarding the mean annual zonally averaged climate simulation are in good agreement with the observations, as it will be seen in section $4 \mathrm{a}$.

\section{b. Atmospheric flux parameterizations for the land fraction of a latitude belt}

The parameterizations of the components of the atmospheric fluxes for the fraction of the earth's surface covered by land are based on that from Saltzman (1968) and are given in Table 3. As can be noted in Table 3, the expression of the longwave radiation is obtained
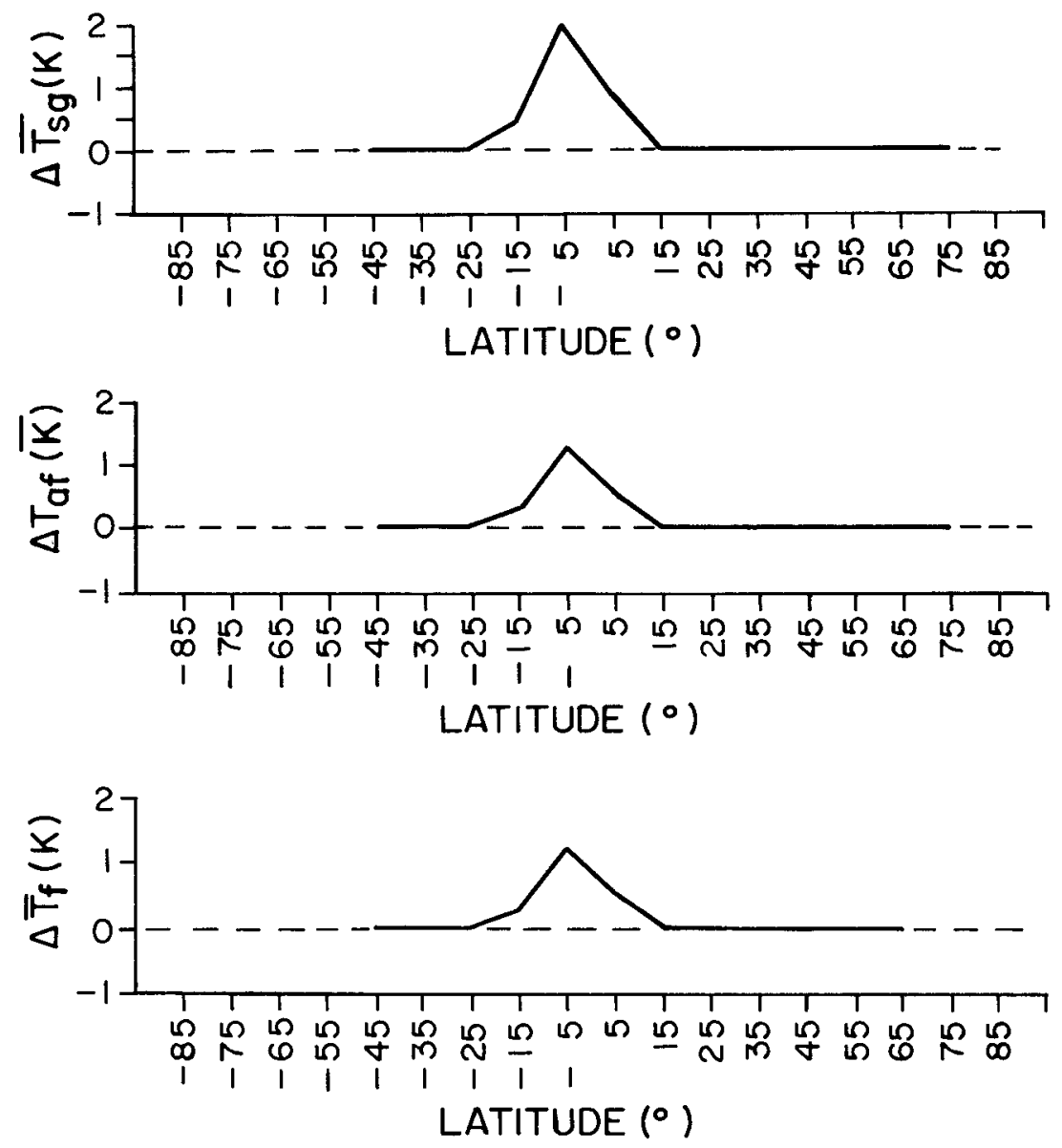

FIG. 6. Changes in the surface temperature $\left(\bar{T}_{\mathrm{sg}}\right)$, foliage $\left(\bar{T}_{\mathrm{f}}\right)$, and foliage air-layer $\left(\bar{T}_{\mathrm{af}}\right)$ temperatures (perturbed minus control case) in the continental portion of the latitude belt for the deforestation experiment. 


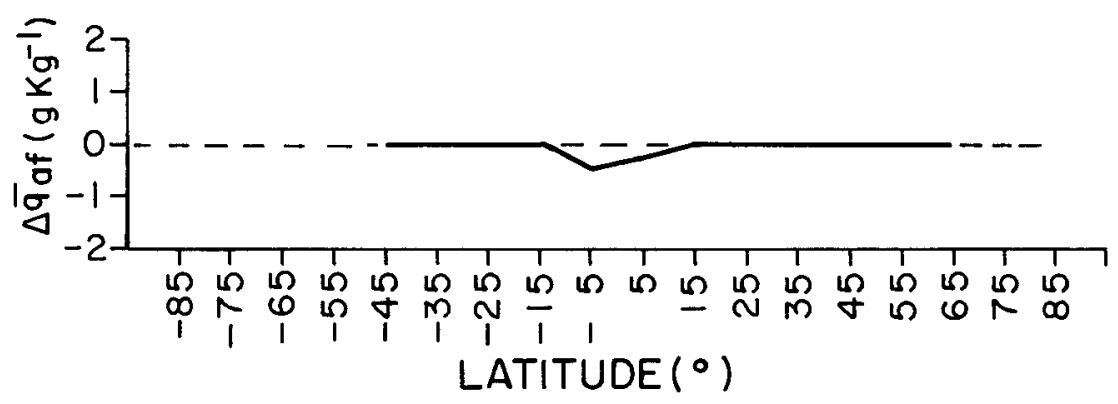

FIG. 7. Changes in the specific humidity at surface (perturbed minus control case) in the continental portion of the latitude belt for the deforestation experiment.

taking into account both the contributions due to the soil surface $\left[\left(1-\sigma_{\mathrm{f}}\right) \bar{T}_{\mathrm{sg}}^{4}\right]$ and due to the foliage $\left(\sigma_{\mathrm{f}} \bar{T}_{\mathrm{f}}^{4}\right)$.

c. Surface and atmospheric parameterizations for the fraction of the earth's surface covered by ocean, ice, and snow

Regarding the fraction of the earth's surface covered by ocean, ice, and snow the model contains three domains: the subsurface layer, the air layer adjacent to surface, and the atmospheric layer.

The parameterizations of the surface and atmospheric fluxes for this portion of a latitude belt are comparable to those from the vegetation model (section 2) but only the effects of ocean-ice-snow are considered. The formulations of these fluxes are given in Table 5, where the subscript "o" refers to the ocean and ice portion, and the bars correspond to the zonal average in this region. The symbols are given in the appendix. The energy balance at the surface is given by

$$
\sum \bar{H}_{\mathrm{so}}(i) \downarrow=0 .
$$

Similar to expression (2), the heat flux from surface is balanced by the heat flux to the atmosphere:

$$
\bar{H}_{\mathrm{ao}}(3)=\bar{H}_{\mathrm{so}}(3) \uparrow \text {. }
$$
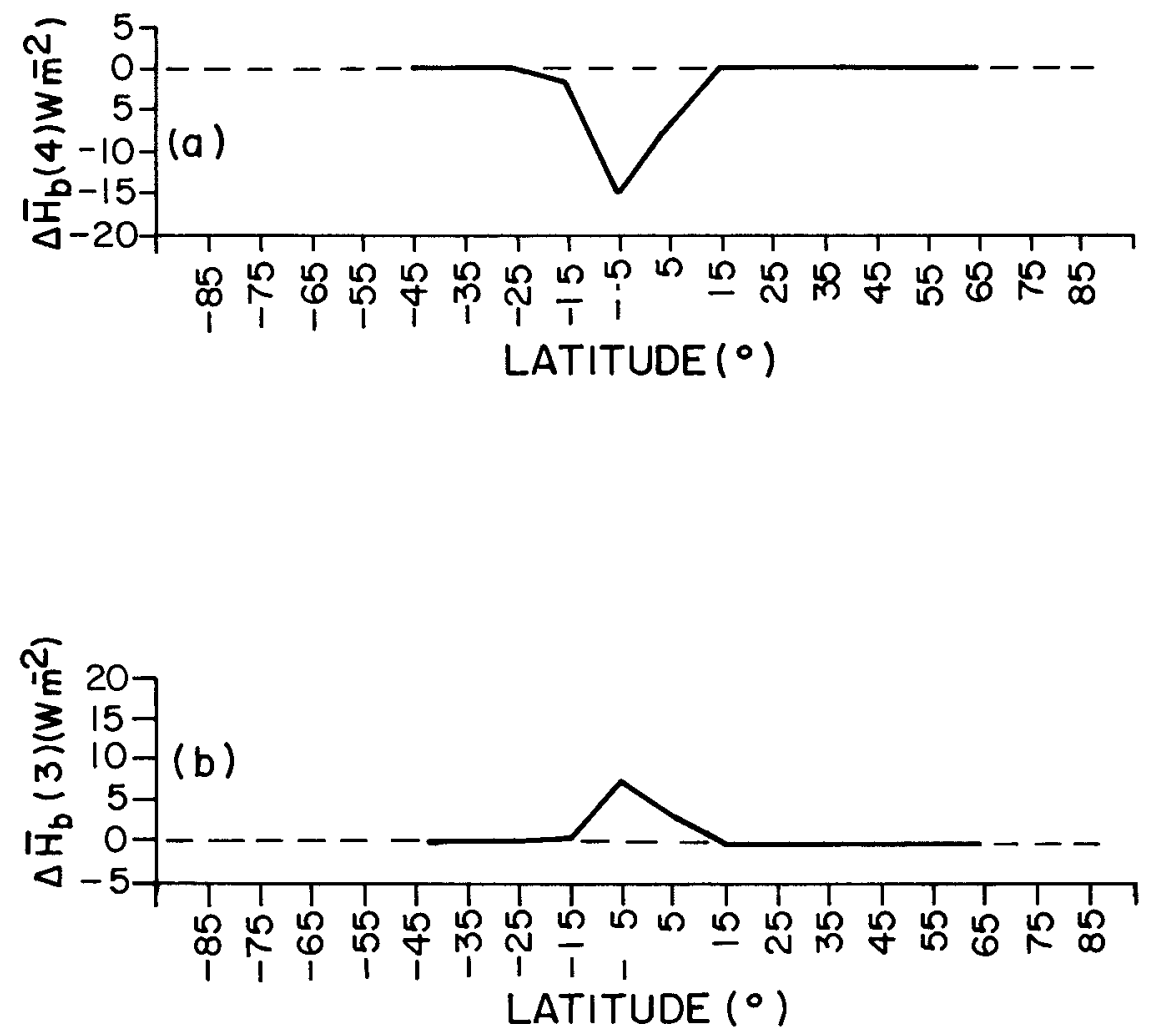

FIG. 8. Changes in the latent heat flux (a) and in the sensible heat flux (b) from surface to atmosphere (perturbed minus control case) in the continental portion of the latitude belt for the deforestation experiment. 

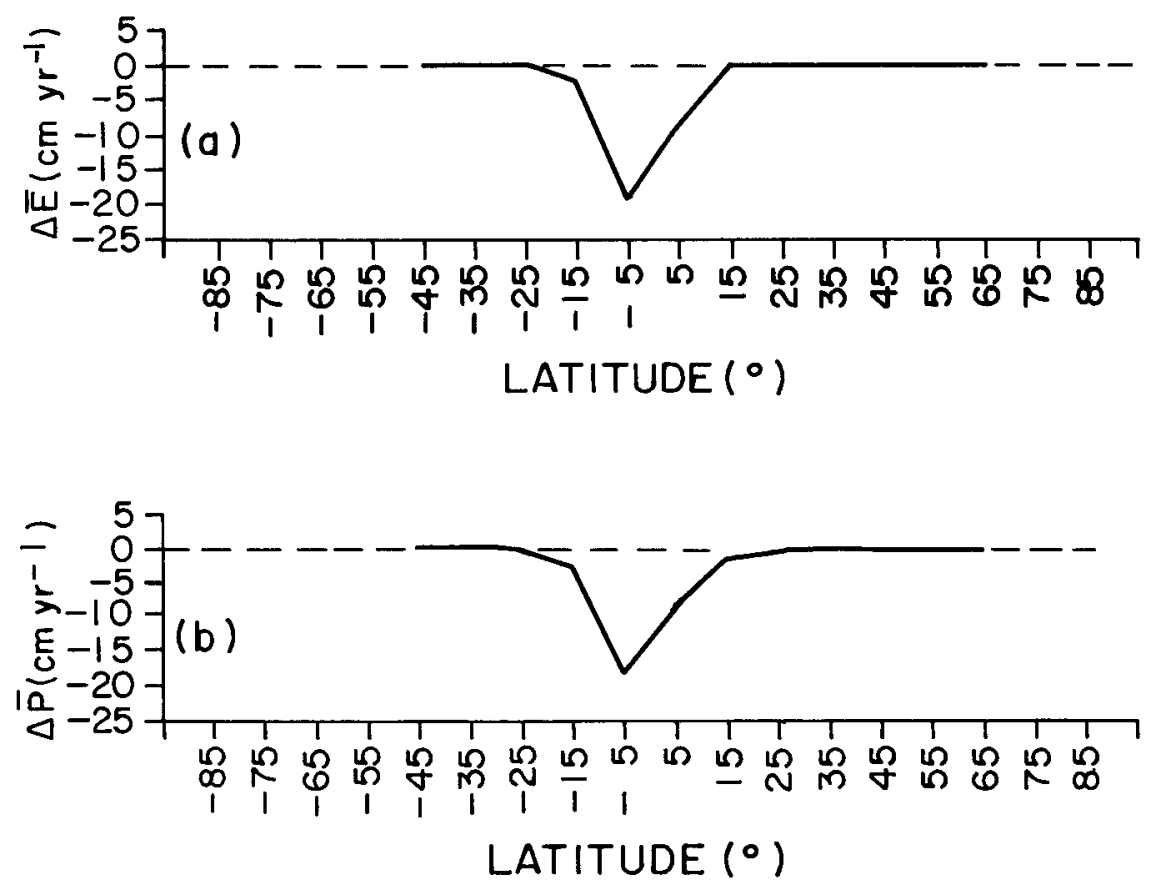

FIG. 9. Changes in the evapotranspiration (a) and precipitation (b) (perturbed minus control case) in the continental portion of the latitude belt for the deforestation experiment

Also, similar to relation (4), the water vapor flux from surface is balanced by the water vapor flux to atmosphere:

$$
\bar{E}_{\mathrm{bo}}=\bar{E}_{\mathrm{so}},
$$

where $\bar{E}_{\mathrm{bo}}=w\left[e_{2} \bar{H}_{\mathrm{so}}(3) \downarrow+f_{2}\right] / L$ and $\bar{E}_{\mathrm{so}}=\bar{H}_{\mathrm{so}}(4) \downarrow / L$.

Substitution of the relations given in Table 5, together the expressions (12)-(14), along the saturated mixing ratio equation produce a closed system with five unknown variables: $\bar{T}_{\text {ao }}, \bar{T}_{\text {so }}, \bar{q}_{\text {ao }}, \bar{q}_{\text {so }}$, and $\bar{q}_{\text {aos }}$. This system

TABLE 4. Values of the nondimensional adjustable factor for the relative humidity $(\mathrm{Y})$, the soil water availability $\left(\mathrm{f}_{\mathrm{g}}\right)$, and the parameter $W_{\mathrm{dw}}=W_{\mathrm{dew}} / W_{\mathrm{dmax}}$, for each vegetation type.

\begin{tabular}{lccc}
\hline \hline \multicolumn{1}{c}{ Vegetation type } & $Y$ & $f_{\mathrm{g}}$ & $W_{\mathrm{dw}}$ \\
\hline Crop/mixed farming & 0.8 & 0.125 & 0.035 \\
Short grass & 0.7 & 0.083 & 0.035 \\
Evergreen needleaf tree & 1.0 & 0.042 & 0.014 \\
Deciduous needleaf tree & 1.0 & 0.042 & 0.007 \\
Deciduous broadleaf tree & 1.0 & 0.125 & 0.028 \\
Evergreen broadleaf tree & 1.0 & 0.333 & 0.052 \\
Tall grass & 0.7 & 0.125 & 0.031 \\
Desert & 0.6 & 0.000 & 0.000 \\
Tundra & 0.9 & 0.042 & 0.010 \\
Irrigated crop & 0.7 & 0.250 & 0.021 \\
Semidesert & 0.5 & 0.000 & 0.003 \\
Ice cap/glacier & 0.5 & - & - \\
Bog or marsh & 1.0 & 0.292 & 0.021 \\
Inland water & 1.0 & 1.000 & - \\
Ocean & 1.0 & 1.000 & - \\
Evergreen shrubs & 0.8 & 0.083 & 0.021 \\
Deciduous shrubs & 0.7 & 0.042 & 0.021 \\
Mixed woodland & 1.0 & 0.166 & 0.031 \\
\hline
\end{tabular}

of equations is solved using a Newton-Raphson method similar to that used in the vegetation model (section 2).

\section{d. Surface and atmospheric fluxes for a latitude belt as a whole}

The values of the components of surface and atmospheric fluxes for a latitude belt as a whole are obtained through the weighted mean of these values for the fractions of the earth's surface covered by land and by ocean-ice-snow, using as weight the portions of land and ocean-ice-snow in a latitude belt. The surface temperature in a latitude belt is computed in a similar way.

The SDM gives the zonally averaged variables: temperature at $500 \mathrm{hPa}$, wind speed at the anemometer level, and the subsurface temperature, which are necessary to calculate the energy fluxes for the fraction of the earth's surface covered by vegetation. These fluxes provide the diabatic heating for the zonally averaged atmosphere, affecting the climate. Thus, the vegetation acts as an interactive element of the climate system. The latitudinal values of the subsurface temperature used in the model are those from Saltzman and Vernekar (1971). The wind speed at the anemometer level is assumed to be equal to the zonally averaged wind at $750 \mathrm{hPa}$. This assumption is compatible with the parameterization of the friction used in the SDM, where the surface wind is approximated by the zonally averaged wind at $750 \mathrm{hPa}$ in order to satisfy the condition that the friction must dissipate kinetic energy (Charney 1959; Taylor 1980). However, this is different in Zhang's model. In his case, 
TABLE 5. Parameterizations of the surface $\left[\bar{H}_{\mathrm{so}}(i)\right]$ and atmospheric $\left[\bar{H}_{\mathrm{ao}}(i)\right]$ fluxes for the fraction of the earth's surface covered by ocean, ice, and snow. The arrows indicate the direction of the fluxes.

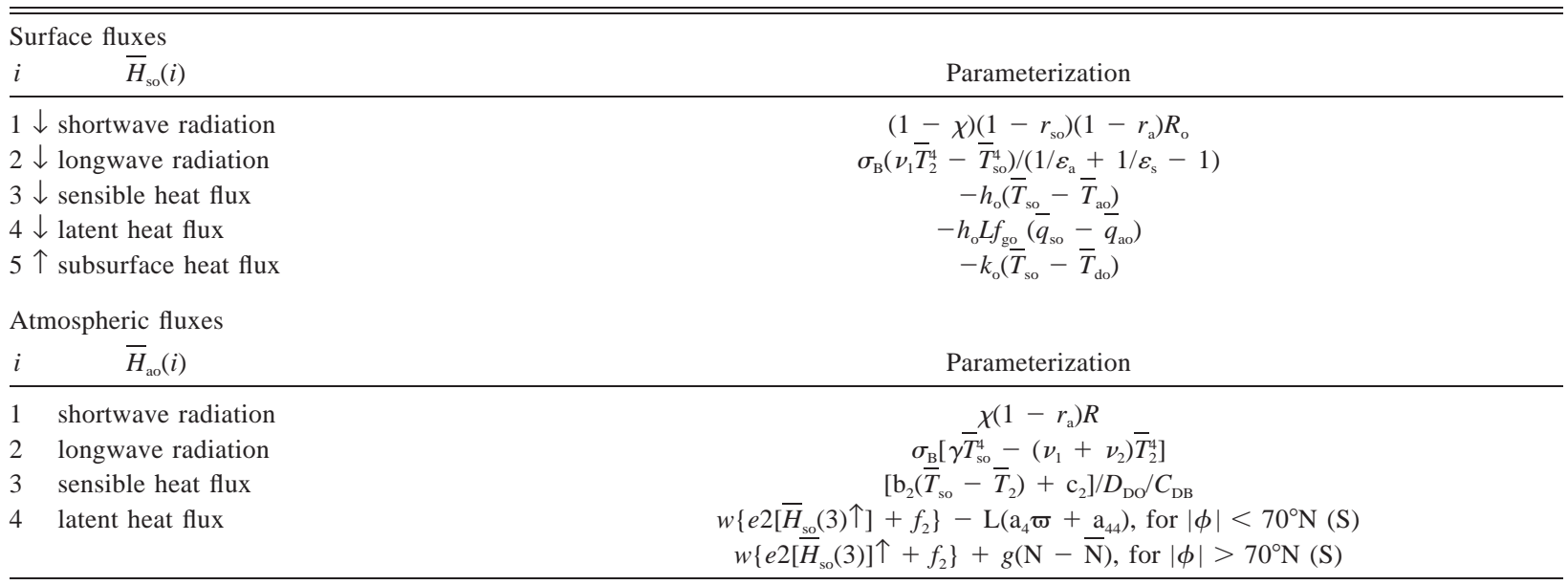

the wind speed at the anemometer level is a prescribed variable.

\section{e. Initial conditions}

The coupled model has $10^{\circ}$ lat resolution and employs a latitudinal centered finite-differencing scheme. The strategy for obtaining the solutions of the coupled model is different to that used in the original SDM. In the latter, the initial condition was an isothermal atmosphere $(270 \mathrm{~K})$ at rest. An explicit time integration was used with a time step of $30 \mathrm{~min}$. The model was integrated for six months forced by mean annual conditions in order to obtain stationary solutions. Thus, the energy fluxes were computed considering the entire latitude belt. In the present coupled model, these fluxes are calculated separately for the land and the remaining part of the latitude belt (sections $3 \mathrm{a}-\mathrm{c}$ ). Since the values of the temperature at $500 \mathrm{hPa}$ and the wind speed are necessary to run the coupled model (and they cannot be zero even in the initial conditions), we use as initial condition the mean annual zonally averaged simulation obtained with the original SDM. Then, the coupled model is run forced by the mean annual conditions in order to obtain the energy fluxes for both the land fraction and the remaining part of the latitude belt. The weighted mean of the energy fluxes for the entire latitude belt are computed using as weight the portions of land and ocean-ice-snow (section 3d).

Thus, the coupled model contains a more detailed treatment of the biosphere processes than in the case of the original SDM and provides the values of the energy fluxes both in the continental region covered by vegetation and in the entire latitude belt. As mentioned in section $3 \mathrm{~d}$, in the coupled model the vegetation is an interactive element of climate since the vertical fluxes
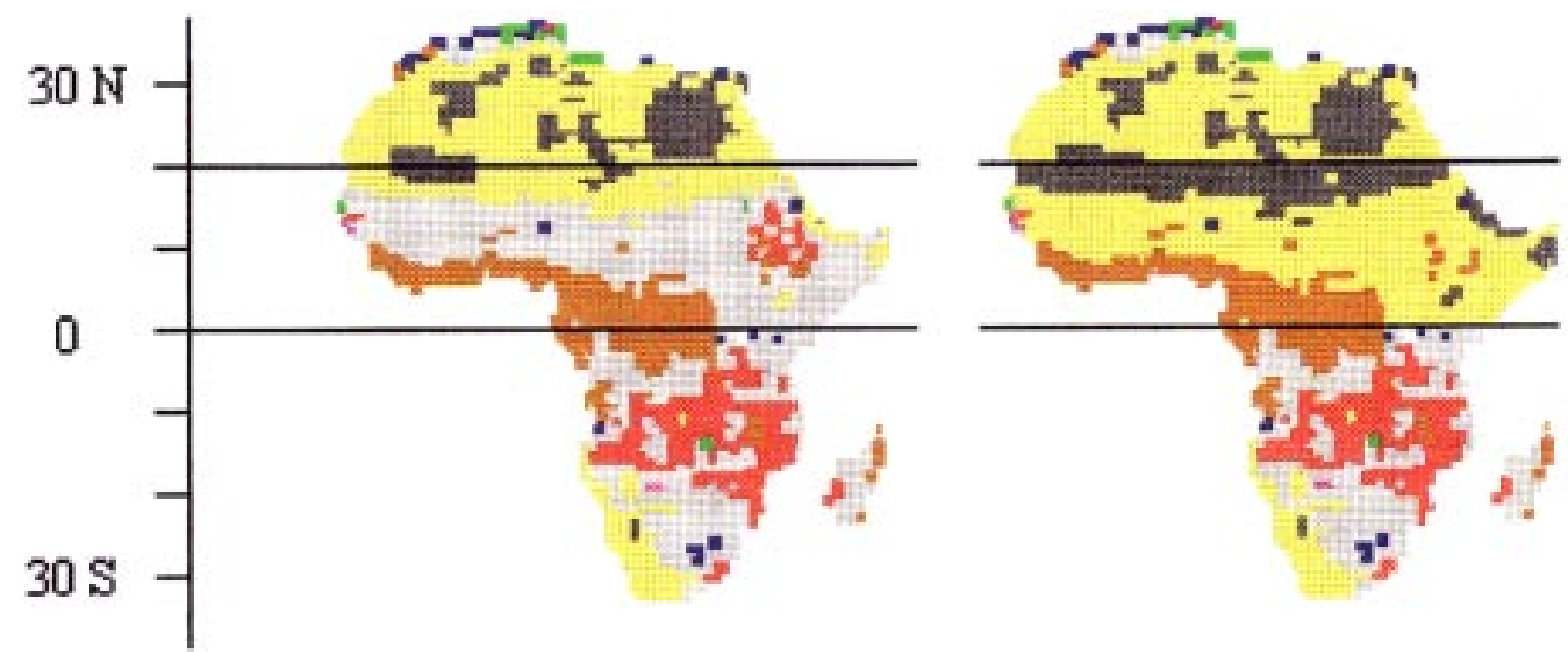

FIG. 10. Africa desertification experiment: control case (left) and perturbed case (right). The legend colors are the same as in Fig. 2. 


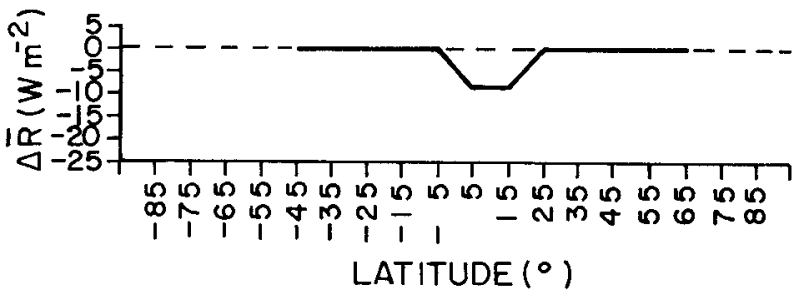

FIG. 11. Changes in the surface net radiation (perturbed minus control case) in the continental portion of the latitude belt for the desertification experiment.

in the biosphere model depend on the values of wind and temperature from the atmospheric model, and the diabatic heating in the atmospheric model, in turn, depends on the vertical fluxes from the biosphere.

\section{Results}

This section is divided in two parts: in the first part the simulations of the mean annual zonally averaged climate and the surface fluxes in the geobotanic zones are presented; in the latter part, numerical experiments on land surface modifications like deforestation and desertification are discussed.

\section{a. Simulation of the mean annual zonally averaged climate}

The coupled biosphere-SDM is run in order to simulate the mean annual zonally averaged characteristics and the surface fluxes in the geobotanic zones.

Figures $3 \mathrm{a}-\mathrm{h}$ show the model simulations of the mean annual zonally averaged surface temperature, temperature at the level of $500 \mathrm{hPa}$, zonal winds at 250 and $750 \mathrm{hPa}$, vertical velocity $\bar{\omega}$, specific humidity at surface, and precipitation, respectively. The observed data are from Oort (1983) (Figs. 3a-f) and from Budyko (1978) (Fig. 3g).

It can be seen in Figs. 3a-b that the surface and 500$\mathrm{hPa}$ temperatures are well simulated. The larger differences between the simulation and the observations occur only near poles. In general, the temperature deviations from the observations are in the same direction, so the temperature gradient (surface-500 hPa) is well simulated.

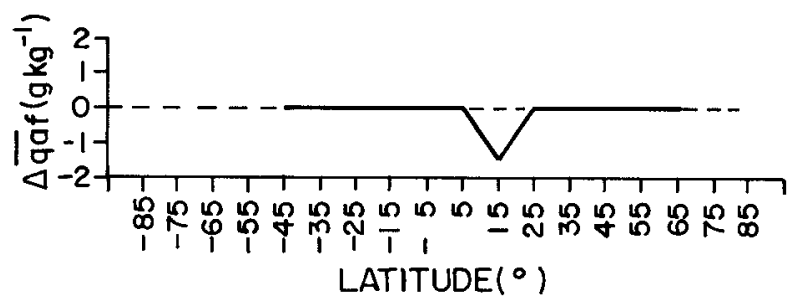

FIG. 12. Changes in the specific humidity at the surface (perturbed minus control case) in the continental portion of the latitude belt for the desertification experiment.

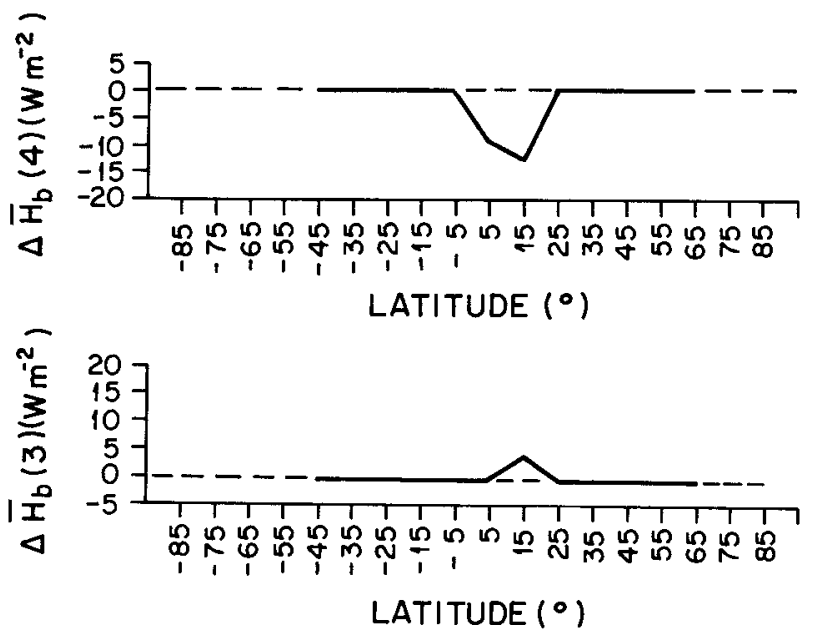

FIG. 13. Changes in the latent heat flux (a) and sensible heat flux (b) from surface to atmosphere (perturbed minus control case) in the continental portion of the latitude belt for the desertification experiment.

Figures $3 \mathrm{c}$, d show that the general form of the latitudinal variation of the mean annual zonally averaged zonal wind at 250 and $750 \mathrm{hPa}$, respectively, are well simulated, although the simulation is better for the case of the 250-hPa zonal wind. This was also noted in other model simulations, like in Ohring and Adler (1978), Gutman et al. (1984), Franchito and Rao (1992), and many others. As can be seen in Figs. 3c,d, the positions of the maxima are well simulated and the model values in the tropical region are close to the observed data. The magnitude of the model maxima in the Northern Hemisphere are in agreement with the observations, while in the Southern Hemisphere they are underestimated.

The simulation of the vertical velocity at $500 \mathrm{hPa}$ is
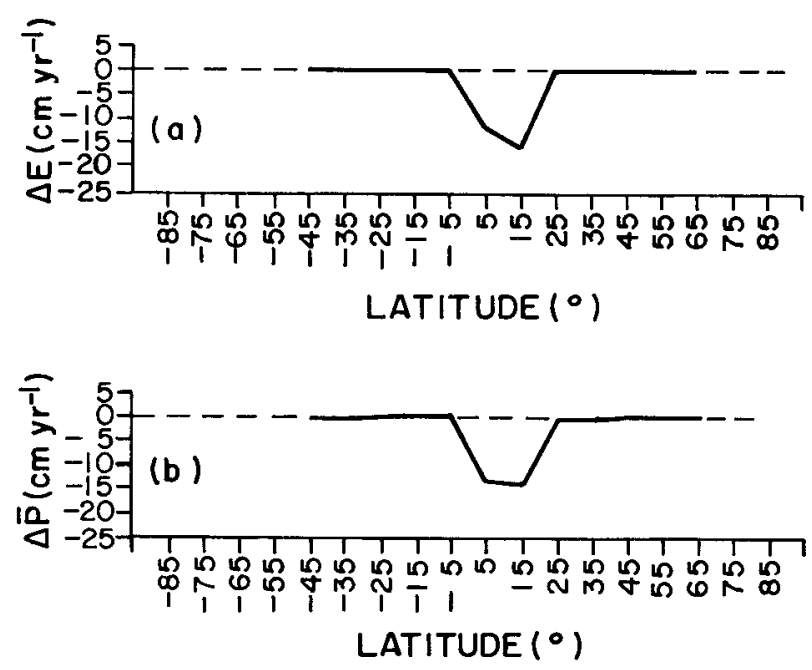

FIG. 14. Changes in the evapotranspiration (a) and precipitation (b) (perturbed minus control case) in the continental portion of the latitude belt for the desertification experiment. 


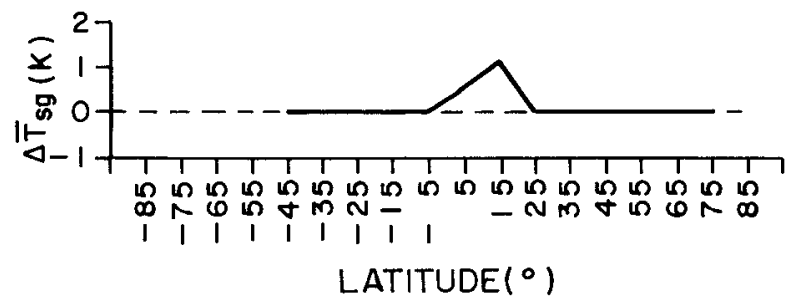

FIG. 15. Changes in the surface temperature (perturbed minus control case) in the continental portion of the latitude belt for the desertification experiment.

shown in Fig. 3e. The three cells of the mean meridional circulation can be seen: the ascending motion region in low latitudes, the subsidence zone from $15^{\circ}$ to $45^{\circ} \mathrm{N}(\mathrm{S})$, the convergence zone in temperate latitudes, and a region of subsidence near poles.

The latitudinal variation of the surface specific humidity is well simulated by the model, as can be seen in Fig. 3f. Figure 3g shows the latitudinal variation of the precipitation. As can be noted, the simulated values are in good agreement with the observations. The maximum at equator and the values in the tropical region are well simulated by the model. The secondary maxima are also well reproduced by the model.

In general, these results are similar to those obtained from the original SDM (Franchito and Rao 1992). However, there is a good improvement in the simulations of the zonal wind at $250 \mathrm{hPa}$ and of the precipitation. The parameterization of precipitation in the model is similar to that proposed by Gutman et al. (1984): for the latitudes near poles the precipitation depends upon the evaporation and a correction that depends on the difference between the cloudiness amount in a latitude belt and the hemispheric mean; for the other latidude belts the precipitation depends on the evaporation and the vertical velocity (and consequently on the water vapor flux convergence). Since the values of the vertical velocity are similar to those from Franchito and Rao (1992), the improvement in the precipitation is due mainly to evaporation. Thus, when a biosphere model is coupled to the SDM, the treatment of the heat fluxes is more realistic, and consequently there is an improvement in the model results.

Figure $3 \mathrm{~h}$ shows the simulated mean annual values of the surface net radiation, and the sensible and latent heat fluxes for the continental portion of the latitude belts. In these fluxes the effect of all types of vegetation that exist in the latitude belt is considered. Since the mean annual value of the subsurface heat flux is zero, the available radiation is partitioned into sensible and latent heat fluxes. As can be seen in Fig. 3h, this energy partition occurs in most part in the form of latent heat flux. Also, the net radiation and the latent heat flux increase rapidly toward the equator (in the direction of greater vegetation cover), while the sensible heat flux variation is smaller.

The simulation of the mean annual zonally averaged climate is taken as the control experiment in the next section.

\section{b. Numerical experiments on land surface modifications}

The coupled biosphere-SDM is run to study the climatic impact due to two cases of land surface modifications: deforestation and desertification, as described below.

\section{1) Deforestation case}

In this experiment the climatic effects of the Amazonian deforestation are simulated, where the evergreen broadleaf tree is replaced by short grass in South America from $10^{\circ} \mathrm{S}$ to $10^{\circ} \mathrm{N}$, as shown in Fig. 4. So, all the characteristic parameters of the tropical forest are replaced by those from short grass conditions according to BATS. The values of the variables used in the continental area of the latitude belt are obtained through the weighted mean of the specific values using as weight the fraction of each type of vegetation in the latitude belt, but replacing the evergreen broadleaf trees with short grass.

The results are given by the differences between the perturbed and control cases. The changes in the surface net radiation; surface, foliage, and foliage air layer temperatures; specific humidity in the foliage air layer; latent heat flux; sensible heat flux; evapotranspiration; and precipitation, considering the continental areas of the latitude belts, are shown in Figs. 5-9, respectively. It can be seen that the greatest changes occur in the perturbed region. This agrees with previous studies, like

TABLE 6. Changes in the air surface temperature, precipitation, and evapotranspiration for deforestation experiments: results of GCM studies and of the present model. The biosphere scheme used in these models is indicated.

\begin{tabular}{lccr}
\hline \hline \multicolumn{1}{c}{ GCMs studies } & Biosphere scheme & $\Delta T_{\mathrm{a}}(\mathrm{K})$ & $\Delta P\left(\mathrm{~cm} \mathrm{yr}^{-1}\right)$ \\
\hline Henderson-Sellers and Gornitz (1984) & & 0.0 & -21.9 \\
Dickinson and Henderson-Sellers (1988) & BATS & +1 to +3 & -15 to -18 \\
Nobre et al. (1991) & SiB & +2.0 & -20.0 \\
Manzi (1993) & ISBA & +1.3 & -64.0 \\
Lean and Rowntree (1993) & SiB & +2.1 & -1.5 \\
Sud et al. (1996) & Based on BATS & +0.7 & -29.6 \\
Present model & & +1.2 & -6.1 \\
\hline
\end{tabular}


TABLE 7. Surface energy budget: comparisons between results of a SiB scheme (GCM) and the present model.

\begin{tabular}{|c|c|c|c|c|c|c|c|}
\hline Model & Scheme & Run & $\begin{array}{c}R \\
\left(\mathrm{~W} \mathrm{~m}^{-2}\right)\end{array}$ & $\begin{array}{c}L_{\mathrm{n}} \\
\left(\mathrm{W} \mathrm{m}^{-2}\right)\end{array}$ & $\begin{array}{c}H_{\mathrm{b}}(3) \\
\left(\mathrm{W} \mathrm{m}^{-2}\right)\end{array}$ & $\begin{array}{c}H_{\mathrm{b}}(4) \\
\left(\mathrm{W} \mathrm{m}^{-2}\right)\end{array}$ & $\begin{array}{c}T_{\mathrm{sg}} \\
(\mathrm{K})\end{array}$ \\
\hline GCM (Nobre et al. 1991) & $\mathrm{SiB}$ & Control & 172 & 32 & 44 & 128 & 296.6 \\
\hline Present SDM & Based on BATS & Control & 157.5 & 56.8 & 37.0 & 120.5 & 295.1 \\
\hline GCM (Nobre et al. 1991) & $\mathrm{SiB}$ & Deforestation & 146 & 40 & 56 & 90 & 299.2 \\
\hline Present SDM & Based on BATS & Deforestation & 149.8 & 59.6 & 44.5 & 105.3 & 297.1 \\
\hline
\end{tabular}

Potter et al. (1975), Gutman (1984), and Franchito and Rao (1992). However, differently from Franchito and Rao (1992), the perturbation in the land state surface has a greater effect in the Southern Hemisphere, which contains most of the Amazonian forest. This result is a consequence of the detailed parameterization of the biosphere, which permits us to consider separately each type of vegetation in a latitude belt. This is an improvement of the SDM, because in the original version of the model the perturbation was imposed in the entire latitude belt.

The analysis of Figs. 5-9 shows that the surface net radiation decreases $\left(7.7 \mathrm{~W} \mathrm{~m}^{-2}\right.$ at $\left.5^{\circ} \mathrm{S}\right)$ due to the greater land surface albedo and consequent reduction of the absorbed radiation flux in the deforested case compared to the control case. The surface temperature is warmer $\left(2.0 \mathrm{~K}\right.$ at $\left.5^{\circ} \mathrm{S}\right)$ in the deforestation relative to the control experiment. This warming occurs in the foliage air layer, so that there is an increase in the foliage temperature $\left(1.3 \mathrm{~K}\right.$ at $\left.5^{\circ} \mathrm{S}\right)$ and in the foliage air layer temperature $\left(1.2 \mathrm{~K}\right.$ at $\left.5^{\circ} \mathrm{S}\right)$. At the foliage air layer, the specific humidity decreases $\left(0.5 \mathrm{~g} \mathrm{Kg}^{-1}\right.$ at $\left.5^{\circ} \mathrm{S}\right)$ in the deforested case compared to the control case. Since the specific humidity decreases and the temperature increases in the foliage air layer, there is a decrease in the relative humidity $(7.6 \%)$. Consequently, the latent heat flux from surface is lower $\left(15.2 \mathrm{~W} \mathrm{~m}^{-2}\right.$ at $\left.5^{\circ} \mathrm{S}\right)$ in the deforestation case relative to the control experiment. As the foliage air layer temperature is higher, there is an increase in the sensible heat flux from surface to the atmosphere $\left(7.5 \mathrm{~W} \mathrm{~m}^{-2}\right.$ at $\left.5^{\circ} \mathrm{S}\right)$, which partially compensates the decrease in the latent heat flux in the deforested case compared to the control case. Also, the evapotranspiration decreases in the perturbed region $\left(18.9 \mathrm{~cm} \mathrm{yr}^{-1}\right.$ at $5^{\circ} \mathrm{S}$ ), consistent with the warming that extends from surface to the foliage air layer. Consequently, there is a decrease in the precipitation $\left(17.9 \mathrm{~cm} \mathrm{yr}^{-1}\right.$ at $\left.5^{\circ} \mathrm{S}\right)$ in the deforested case relative to the control experiment.

These results are in agreement with those obtained from GCMs (e.g., Sud et al. 1996; Lean and Rowntree 1993; Nobre et al. 1991) and some observations (Ghuman and Lal 1987; Lawson et al. 1981) for tropical forest.

Tables 6-7 show some results of the present model regarding the changes in the continental portion of the latitude belt centered at $5^{\circ} \mathrm{S}$, and those obtained from GCMs using different schemes for the treatment of the biosphere. As can be seen, in general, the changes in the present model occur in the same direction as those from the GCMs. The differences in the magnitude of the changes may be attributed to the differences between the present coupled model and the GCMs such as the resolution, the treatment of radiative processes and clouds, planetary boundary layer modeling and coupling of the surface to the atmosphere, treatment of snow and ice, etc. Also, it must be noted that the present model
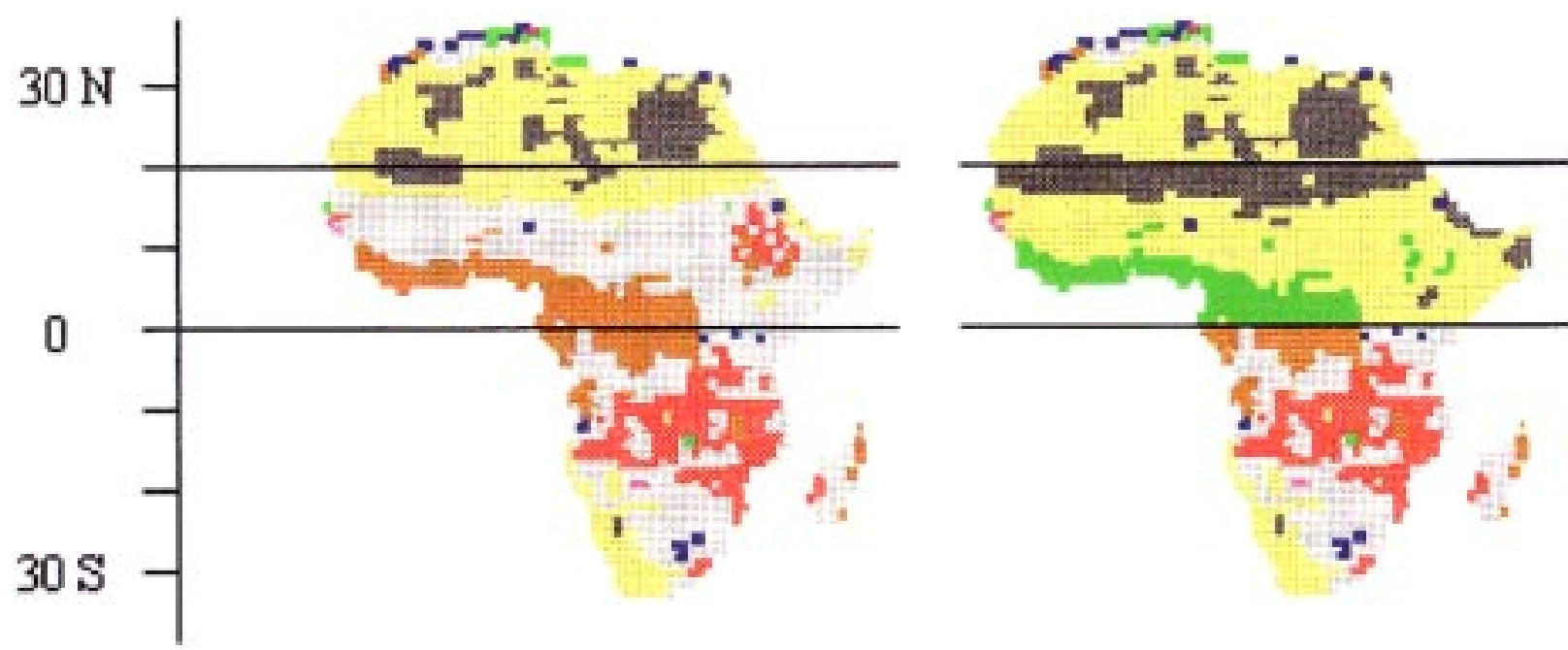

FIG. 16. Experiment considering the degradation of the vegetation in African continent from $0^{\circ}-20^{\circ} \mathrm{N}$, including the modification in the tropical forest: control case (left) and perturbed case (right). The legend colors are the same as in Fig. 2. 

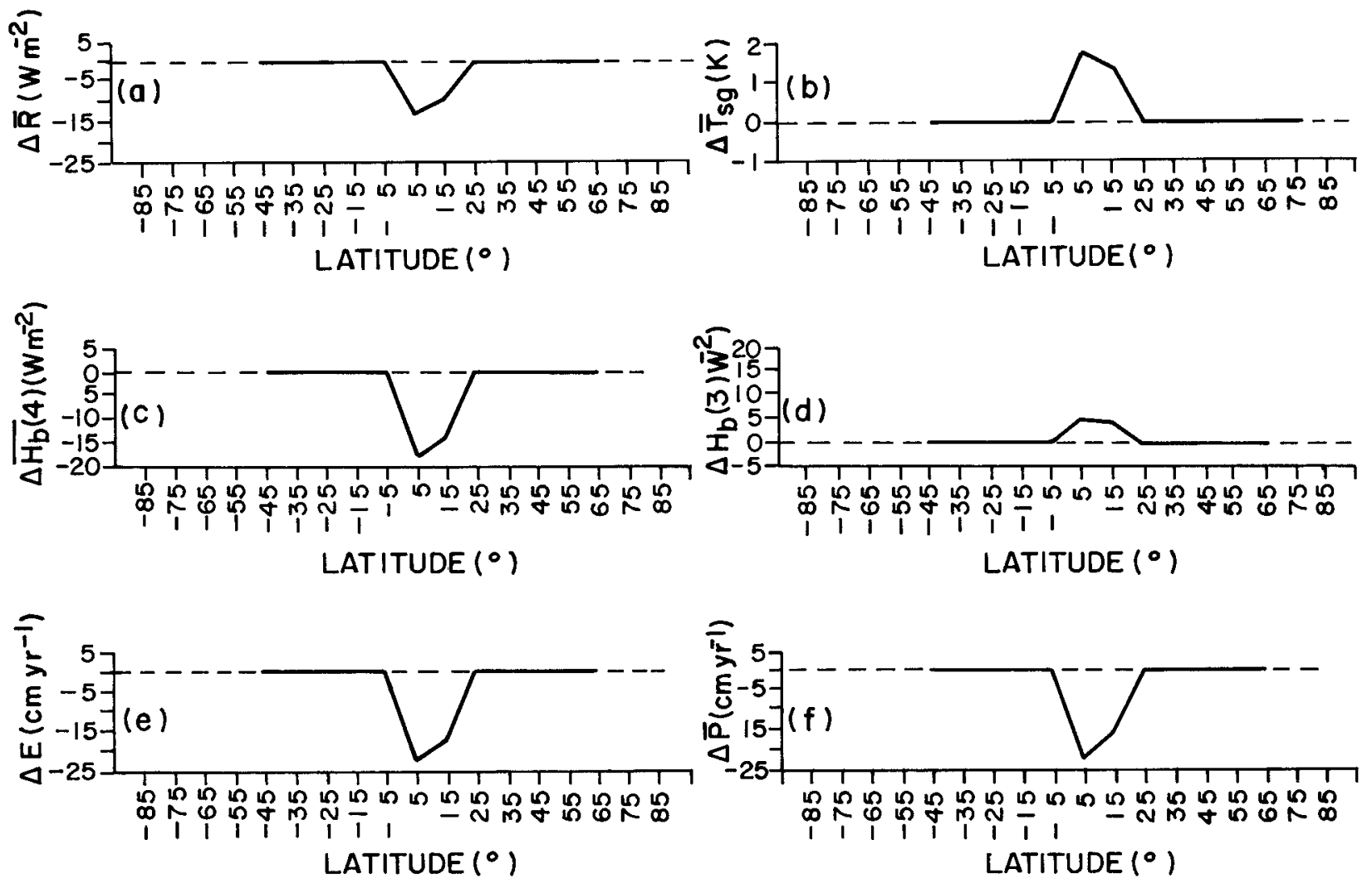

FIG. 17. Changes in the surface net radiation (a), surface temperature (b), latent heat flux (c), sensible heat flux (d), evapotranspiration (e), and precipitation (f) (perturbed minus control) in the continental portion of the latitude belt for the experiment of degradation of vegetation including the modification of tropical forest in the African continent from $0^{\circ}$ to $20^{\circ} \mathrm{N}$.

is a zonally averaged model and the results shown refer to the changes in the continental area of the latitude belt and not to a smaller regional area as in the case of GCMs. Therefore, we can expect differences in the magnitude of the changes compared to those from GCMs. However, the climate response to altered surface conditions is consistent with that obtained from GCM simulations, showing that the present model is a good complement to GCMs.

The model results concerning the deforestation experiment are also consistent with those obtained from other SDMs, which used parameterization of the biofeedback mechanisms much simpler than BATS (Franchito and Rao 1992; Gutman 1984). However, in the earlier studies the perturbation was imposed in the entire land fraction of the latitude belt, whereas in the present model we can study the effects of a land surface modification in a determined region of a latitude belt, such as the Amazonian forest. This advantage in comparison with the other SDM studies is due to the use of a detailed parameterization of the biosphere (based on BATS), as mentioned earlier.

\section{2) DESERTIFICATION CASE}

In this experiment the climatic impact of an anthropogenic degradation of the vegetation situated south- ward of the Sahara desert is simulated. The land surface modification consists in the substitution of semidesert by desert, and tall grass and deciduous shrubs by desert and semidesert, respectively, in the African continent from $0^{\circ}$ to $20^{\circ} \mathrm{N}$ (Fig. 10). The characteristic parameters of these vegetation types in a latitude belt are obtained analogously to the deforestation case.

As can be seen in Figs. 11-15, the changes are qualitatively similar to those from the deforestation case. There is a reduction in the net surface radiation $(8.3 \mathrm{~W}$ $\left.\mathrm{m}^{-2}\right)$, specific humidity in the foliage air layer $(1.6 \mathrm{~g}$ $\left.\mathrm{Kg}^{-1}\right)$, latent heat flux $\left(12.9 \mathrm{~W} \mathrm{~m}^{-2}\right)$, evapotranspiration (16.0 $\left.\mathrm{cm} \mathrm{yr}^{-1}\right)$, precipitation (14.2 $\mathrm{cm} \mathrm{yr}^{-1}$ ), and an increase in the sensible heat flux $\left(4.6 \mathrm{~W} \mathrm{~m}^{-2}\right)$ and in the surface temperature $(1.1 \mathrm{~K})$ in the perturbed region. The values in parentheses refer to the continental portion of the latitude belt centered at $15^{\circ} \mathrm{N}$. Comparisons with other desertification experiments carried out with GCMs (Table 8) show that the the changes occur in the same direction. This indicates again the usefulness of the present coupled model as a complementary tool for GCMs in climatic change studies related to land surface modifications.

In general, the changes are greater in the latitude belt centered at $15^{\circ} \mathrm{N}$, where the amount of tall grass and deciduous shrubs, which are substituted by semidesert, 
TABLE 8. Changes in the ground temperature, air surface temperature, precipitation, and evapotranspiration for desertifications experiments: results of GCM studies and of the present model.

\begin{tabular}{|c|c|c|c|c|}
\hline GCMs studies & $\Delta T_{\mathrm{sg}}(\mathrm{K})$ & $\Delta T_{\mathrm{a}}(\mathrm{K})$ & $\Delta P\left(\mathrm{~mm} \mathrm{day}^{-1}\right)$ & $\Delta E\left(\mathrm{~mm} \mathrm{day}^{-1}\right)$ \\
\hline Charney et al. (1977) & & & -1.58 & \\
\hline Laval and Picon (1986) & & & -0.75 & -0.50 \\
\hline Xue and Shukla (1993) & & +0.5 & -1.50 & -0.70 \\
\hline Dirmeyer and Shukla (1996) & +0.3 to +1.2 & & -0.3 to -1.5 & \\
\hline Present model & +1.1 & +0.7 & -0.39 & -0.44 \\
\hline
\end{tabular}

is greater. Another numerical experiment, where the tropical forest was also degraded (the evergreen broadleaf trees were substituted by short grass) was carried out with the coupled SDM (Fig. 16). The results (Fig. 17) showed that the changes were greater than those of the previous experiment, and the greatest changes occurred in the latitude belt centered at $5^{\circ} \mathrm{N}$. This suggests that the modification of the tropical forest has an important role in the case of the degradation of vegetation southward from the Sahara desert, in the African continent, although the amount of evergreen broadleaf trees is almost the same as that of tall grass and deciduous shrubs in the latititude belt centered at $5^{\circ} \mathrm{N}$.

\section{Summary and conclusions}

This paper investigates the feasibility of using a SDM for studies of climatic change due to land surface modifications. A biosphere model scheme based on BATS is coupled to a primitive equation global SDM for studying the climatic impact due to a deforestation and a desertification situation. To couple the models, the parameterizations of the biosphere scheme are used in the continental portion of a latitude belt. For this purpose, the fraction of the earth's surface covered by each type of vegetation according to BATS for each latitude belt is obtained. Regarding the fraction of the earth's surface covered by ocean, ice, and snow in a latitude belt, new parameterizations similar to those from the biosphere model are developed.

In the control experiment, the coupled biosphereSDM simulates well the mean annual zonally averaged climate characteristics when compared with the observations. In the deforestation case, the climatic impact due to the Amazonian deforestation, where the evergreen broadleaf trees are substituted by short grass in South America from $10^{\circ} \mathrm{S}$ to $10^{\circ} \mathrm{N}$, is studied. In the deforested case compared to the control case the changes in the continental portion of the latitude belt show a decrease in the surface net radiation, the specific humidity in the foliage air layer, the latent heat flux, evapotranspiration and precipitation, and an increase in the sensible heat flux, which compensates partially the reduction in the latent heat flux in the perturbed region. The changes are greater in the latitude belt centered at $5^{\circ} \mathrm{S}$, where most of the Amazonian forest is concentrated. Also, there is an increase in the surface temper- ature, and in the foliage and foliage air layer temperatures. This indicates that the effect of the reduction in the evapotranspiration is greater than that from the increase of the surface albedo when the tropical forest is substituted by short grass. This indeed is the principal physical mechanism responsible for surface air temperature rise in GCMs.

In the desertification case, the climatic impact due to the anthropogenic degradation of the vegetation situated southward from the Sahara desert is studied. The degradation of the vegetation is considered by the substitution of semidesert, and tall grass and deciduous shrubs by desert and semidesert, respectively, in the African continent from $0^{\circ}$ to $20^{\circ} \mathrm{N}$. The changes in the temperatures and in the energy fluxes are qualitatively similar to those obtained from the deforestation experiment. The greatest changes occur in the latitude belt centered at $15^{\circ} \mathrm{N}$. Another experiment considering the African tropical forest degradation (where the evergreen broadleaf trees were substituted by short grass) was made. The results showed that the changes were greater than those of the previous experiment and occurred in the latitude belt centered at $5^{\circ} \mathrm{N}$, suggesting that the modification in the tropical forest has a major role in the degradation of the vegetation southward from the Sahara desert, in the African continent from $0^{\circ}$ to $20^{\circ} \mathrm{N}$. This hypothesis must be confirmed through other model simulations, like those carried out with GCMs.

Finally, the results show that the present coupled model formulation is valuable for estimating climate response to land surface alterations and give credible predictions consistent with more complex and expensive GCM experiments.

Acknowledgments. Thanks are due to Dr. Antonio Ocimar Manzi for the helpful discussions and to the anonymous reviewers for the relevant suggestions for the improvement of the work. This paper forms part of the Ph.D. thesis of the first author.

\section{APPENDIX \\ List of Symbols}

$a_{3}$

$a_{4}$

- Constant that has different values for water and ice

- $0.1 \mathrm{E}-5$ (0.17 E-5) $\mathrm{m} \mathrm{Pa}^{-1}$ for the Northern Hemisphere (Southern Hemisphere) 


$\mathrm{a}_{44}$
$\mathrm{~b}_{2}$
$\mathrm{~b}_{3}$
$\mathrm{c}_{2}$
$\mathrm{c}_{\mathrm{p}}$
$C_{\mathrm{D}}$
$C_{\mathrm{DB}}$
$C_{\mathrm{DL}}$
$C_{\mathrm{DV}}$
$C_{\mathrm{DO}}$

$\mathrm{e}_{2}$

E -Evapotranspiration

$E_{\mathrm{b}} \quad$-Water vapor flux to the atmosphere

$\bar{E}_{\text {bo }} \quad$-Water vapor flux to the atmosphere in the fraction of latitude belt covered by ocean, ice, and snow

$E_{\mathrm{f}} \quad$-Water vapor flux from foliage to the foliage air layer

$E_{\mathrm{f}}^{\text {WET }} \quad$-Evaporation of water on wet foliage

$E_{\mathrm{g}} \quad-$ Water vapor flux from ground

$\vec{E}_{\text {ao }} \quad$-Water vapor flux from surface in the fraction of latitude belt covered by ocean, ice, and snow

$f_{\mathrm{g}}$
$f_{\mathrm{go}}$

- Soil water availability

-Water availability in the fraction of latitude belt covered by ocean, ice, and snow

$f_{2} \quad$-Prescribed constant independent of latitude

g -238.9 (212) $\mathrm{W} \mathrm{m}^{-2}$ for the Northern

(Southern) Hemisphere

$h \quad$-Heat transfer coefficient between the ground surface and the foliage air layer

$h_{\text {o }} \quad$ - Heat transfer coefficient between the surface and the air above it in the fraction of latitude belt covered by ocean, ice, and snow

$\bar{H}_{\mathrm{ao}}(i), i=1,4 \quad$-Atmospheric heat fluxes in the fraction of latitude belt covered by ocean, ice, and snow: shortwave and longwave radiation, sensible and latent heat fluxes

$\left.\bar{H}_{\text {av }}(i)\right), i=1,4$-Atmospheric heat fluxes in the the land fraction of latitude belt: shortwave and longwave radiation, sensible and latent heat fluxes

$H_{\mathrm{b}}(i), i=1,5 \quad-$ Surface heat fluxes at the top of the foliage air layer: shortwave and longwave radiation, sensible and latent heat fluxes, and subsurface heat flux

$H_{\mathrm{f}} \quad-$ Sensible heat flux from foliage

$H_{\mathrm{sg}}(i), i=1,5 \quad$-Surface heat fluxes at the interface between soil surface and the air above it in the biosphere model: shortwave and longwave radiation, sensible and latent heat fluxes, and subsurface heat flux

$\bar{H}_{\mathrm{so}}(i), i=1,5 \quad$-Surface heat fluxes at the interface between surface and the air above it in the fraction of latitude belt covered by ocean, ice, and snow: shortwave and longwave radiation, sensible and latent heat fluxes, and subsurface heat flux

$\bar{H}_{\mathrm{sv}}(i), i=1,5 \quad$-Energy heat fluxes at surface in the land fraction of latitude belt: shortwave and longwave radiation, sensible and latent heat fluxes, and subsurface heat flux

$k$

$k_{\mathrm{o}}$

$\mathrm{K}_{\mathrm{vk}}$

$L$

$L_{\text {ai }}$

$L_{\mathrm{d}}$

$L_{\mathrm{n}}$

$L_{\text {sai }}$

$L_{\mathrm{w}}$

$M_{1}$

$\frac{N}{N}$

$P$

$q_{\mathrm{af}}$

$q_{\mathrm{afs}}$

$\bar{q}_{\text {ao }}$

q

$\bar{q}_{\text {aos }}$

$q_{\mathrm{fs}}$
-Factor proportional to the conductive heat capacity for the biosphere model

-Factor proportional to the conductive heat capacity for the fraction of latitude belt covered by ocean, ice, and snow

- Von Kármán constant

-Vaporization latent heat

- Leaf area index

-Fractional area of leaves free to transpire

-Net longwave radiation

-Leaf-steam area index

-Fractional area of leaves covered by water

-Soil melting factor

-Cloudiness amount in a latitude belt -Cloudiness amount hemispheric mean

-Precipitation

-Water vapor mixing ratio in the foliage air layer

- Saturated water vapor mixing ratio at the temperature $T_{\text {af }}$, in the foliage air layer

-Water vapor mixing ratio in the air surface layer, in the ocean, ice, and snow fractions of latitude belt

- Saturated water vapor mixing ratio at the temperature $T_{\text {ao }}$, in the air surface layer, in the ocean, ice, and snow fractions of latitude belt

- Saturated water vapor mixing ratio at the temperature $T_{\mathrm{f}}$, in the foliage 
$q_{\mathrm{gs}} \quad-$ Saturated water vapor mixing ratio at the temperature $T_{\mathrm{sg}}$, at the interface between soil surface and the air above it
-Albedo of the atmosphere

-Albedo of the foliage -Longwave albedo of the foliage

-Resistence to the heat or moisture transfer through the laminar boundary layer at the foliage surface

-Albedo of the earth's surface

- Longwave albedo of the earth's surface

\section{-Minimum stomatal resistence}

-Weighted mean of the albedo of the ocean, ice, and snow in the fraction of the earth's surface covered by these types of surface

- Stomatal resistance

-A factor in Eq. (6) that depends on $E_{\mathrm{f}}^{\mathrm{WET}}, L_{\mathrm{w}}, L_{\mathrm{d}}, r_{\mathrm{la}}$, and $r_{\text {stom }}$

- Surface net radiation

-Factor dependent of solar radiation

-Foliage net radiation

- Solar radiation incident at the top of the atmosphere

- Steam area index

-Factor dependent on $T_{\mathrm{f}}$

- Air surface temperature

-Foliage air layer temperature

- Air surface temperature in the ocean-ice-snow fraction of latitude belt

-Subsurface temperature in the ocean-ice-snow fraction of latitude belt

-Foliage temperature

- Surface temperature in the biosphere model

- Surface temperature in the oceanice-snow fraction of latitude belt

- Temperature at $500 \mathrm{hPa}$

-Zonally averaged zonal wind at 250 $\mathrm{hPa}$

—Zonally averaged zonal wind at 750 $\mathrm{hPa}$

-Wind speed in the foliage air layer

-Wind speed at the anemometer level -Adjustable factor for the relative humidity

—Roughness parameter of land

-Roughness parameter of vegetation

-Anemometer level

- Relative humidity

- Total of rainfall intercepted by the canopy

-Capacity the canopy to intercept rainwater $x$

$\varepsilon_{\mathrm{a}}$

$\varepsilon_{\mathrm{f}}$

$\varepsilon_{\mathrm{a}}$

$\phi$

$\gamma$

$\nu_{1}, \nu_{2}$

$\rho_{\mathrm{a}}$

$\sigma_{\mathrm{B}}$

$\sigma_{\mathrm{f}}$

$\bar{\omega}$
-Opacity of the atmosphere to solar radiation

— Thermal emissivity of the earth's surface

- Thermal emissivity of the foliage

- Thermal emissivity of the atmosphere

-Latitude

- Longwave radiation absorbtivity of the atmosphere

-Factors for downward and upward effective blackbody longwave radiation

- Air density at surface

-Stefan-Boltzman constant

-Fractional area of the vegetation cover

-Zonally averaged vertical velocity at $500 \mathrm{hPa}$

\section{REFERENCES}

Budyko, M. I., 1978: Balancing the global heat budget. Climate Change, J. Gribbin, Ed., Cambridge University Press, 85-113.

Charney, J. G., 1959: On the general circulation of the atmosphere. The Atmosphere and Sea in Motion, B. Bolin, Ed., Rockefeller Institute Press, 178-193.

—, P. H. Stone, and W. J. Quirk, 1975: Drought in the Sahara: A biogeophysical feedback mechanism. Science, 187, 434-435.

- W. J. Quirk, S. Chow, and J. Kornfield, 1977: Comparative study of the effects of albedo change on drought in semi-arid regions. J. Atmos. Sci., 34, 1366-1385.

Demidovich, B. P., and I. A. Marion, 1976: Computational Mathematics. Mir, 692 pp.

Dickinson, R. E., 1992: Changes in land use. Climate System Modeling, K. E. Trenberth, Ed., Cambridge University Press, 689-701.

_ , and A. Henderson-Sellers, 1988: Modeling tropical deforestation: A study of GCM land-surface parameterizations. Quart. J. Roy. Meteor. Soc., 114, 439-462.

- - — P. J. Kennedy, and M. F. Wilson, 1986: Biosphere-Atmosphere Transfer Scheme for the NCAR Community Climate Model. NCAR Tech. Note 275+STR, $69 \mathrm{pp}$. [Available from NCAR, P. O. Box 3000, Boulder, CO 80307-3000.]

Dirmeyer, P. A., and J. Shukla, 1994: Albedo as a modulator of climate response to tropical deforestation. J. Geophys. Res., 99 (D10), $20863-20877$.

, and -1996 : The effect on regional and global climate of expansion of the world's deserts. Quart. J. Roy. Meteor. Soc., 122, 451-482.

Elsaesser, H. W., M. C. McCracken, G. L. Potter, and F. M. Luther, 1976: An additional model test of positive feedback from high desert albedo. Quart. J. Roy. Meteor. Soc., 102, 655-666.

Franchito, S. H., and V. B. Rao, 1991: Quasi-geostrophic potential vorticity transport in the Northern and Southern Hemispheres and simple climate models. J. Meteor. Soc. Japan, 69, 233-239.

$\longrightarrow$, and — 1992: Climatic change due to land surface alterations. Climate Change, 22, 1-34.

- , and - 1995: On the simulation of sea surface temperature with a zonally averaged model. Global Atmos. Ocean System, 3, 35-53.

Gates, W. L., 1988: Climate and climate system. Physically-Based Modelling and Simulation of Climate and Climatic Change, M. E. Schlesinger, Ed., Kluwer Academic, 1084 pp.

Ghuman, B. S., and R. Lal, 1987: Effects of deforestation on soil properties and microclimate of a high rain forest in southern $\mathrm{Ni}$ - 
geria. The Geophysiology of Amazonia, R. E. Dickinson, Ed., Wiley, 225-244.

Gutman, G., 1984: Numerical experiments on land surface alterations with a zonal model allowing for interaction between the geobotanic state and climate. J. Atmos. Sci., 41, 2679-2685.

—, G. Ohring, and J. H. Joseph, 1984: Interaction between the geobotanic state and climate: A suggested approach and a test with a zonal model. J. Atmos. Sci., 41, 2663-2678.

Henderson-Sellers, A., 1990: Predicting generalized ecosystem groups with the NCAR CCM: First steps toward an interactive biosphere. J. Climate, 3, 917-939.

— transformations, with particular emphasis on tropical deforestation. Climate Change, 6, 231-257.

— and A. J. Pitman, 1993: Tropical deforestation: Modeling localto regional-scale climate change. J. Geophys. Res., 98 (D4), 72897315 .

Laval, K., and L. Picon, 1986: Effect of a change of the surface albedo on the Sahel on climate. J. Atmos. Sci., 43, 2418-2429.

Lawson, T. L., R. Lal, and K. Oduro-Afriyie, 1981: Rainfall distribution and microclimatic changes over a cleared watershed. Tropical Agriculture Hydrology, R. Lal and E. W. Russel, Eds., John Wiley and Sons, 141-151.

Lean, J., and P. R. Rowntree, 1993: A GCM simulation of the impact of Amazonian deforestation on climate using an improved canopy representation. Quart. J. Roy. Meteor. Soc., 119, 509-530.

Manzi, A. O., 1993: Introduction d'un schema des transferts soil-vegetation-atmosphere dans un modele de circulation generale et aplication a la simulation de la deforestation Amazonienne. Ph.D. thesis, Universite Paul Sabatier, 227 pp.

_ , and S. Planton, 1994: Implementation of ISBA parameterization scheme for land surface processes in a GCM-An annual cycle experiment. J. Hydrol., 155, 353-387.

Nobre, C. A., P. J. Sellers, and J. Shukla, 1991: Amazonian deforestation and regional climate change. J. Climate, 4, 957-987.

Noilhan, J., and S. Planton, 1989: A simple parameterization of land surface processes for meteorological models. Mon. Wea. Rev., 117, 536-549.

Oglesby, R. J., and B. Saltzman, 1990: Extending the EBM: The effect of deep ocean temperature on climate with applications to the Cretaceous. Palaeogeogr. Palaeoclimatol. Palaeoecol., 82, 237259.

Ohring, G., and S. Adler, 1978: Some experiments with a zonally averaged climate model. J. Atmos. Sci., 35, 186-205.

Oort, A. H., 1983: Global atmospheric circulation statistics, 1958-1973. NOAA Prof. Pap. 14, U.S. Government Printing Office, 180 pp.

Potter, G. L., H. W. Elsaesser, M. C. Mac Cracken, and F. M. Luther, 1975: Possible climatic impact of tropical deforestation. Nature, 258, 697-698.

Rao, V. B., and S. H. Franchito, 1993: Response of a simple model to the sea surface anomalies. Ann. Geophys., 11, 846-856.

Sagan, C., B. Toon, and J. B. Pollack, 1979: Anthropogenic albedo changes and the earth's climate. Science, 206, 1363-1368.

Saltzman, B., 1968: Steady-state solutions for the axially-symmetric variables. Pure Appl. Geophys., 69, 237-259.

_, and A. D. Vernekar, 1971: An equilibrium solution for the axiallysymmetric components of the earth's macroclimate. J. Geophys. Res., 76, 1498-1524.

, and - 1972: Global equilibrium solutions for the zonally averaged macroclimate. J. Geophys. Res., 77, 3936-3945.

Sellers, P. J., Y. Mintz, Y. C. Sud, and A. Dalcher, 1986: A simple biosphere $(\mathrm{SiB})$ model for use in general circulation models. $J$. Atmos. Sci., 43, 505-531.

Sud, Y. C., R. Yang, and G. K. Walker, 1996: Impact of in situ deforestation in Amazonia on the regional climate: General circulation model simulation study. J. Geophys. Res., 101 (D3), 70957109.

Taylor, K. E., 1980: The roles of the mean meridional motions and large-scale eddies in zonally averaged circulations. J. Atmos. Sci., 37, 1-19.

Xue, Y., and J. Shukla, 1993: The influence of land surface properties on Sahel climate. Part I: Desertification. J. Climate, 6, 2232-2245.

Zhang, T., 1994: Sensitivity properties of a biosphere model based on BATS and a statistical-dynamical climate model. J. Climate, 7, 890-913. 